\section{The CAG repeat within the androgen receptor gene in male breast cancer patients}

EDITOR-Mutations of the BRCA1 and BRCA2 tumour suppressor genes have been identified in some cases of familial and early onset breast cancer. ${ }^{12}$ Mutations of these genes, however, account for a relatively small proportion of the total cases of female breast cancer. Male breast cancer is a very rare disease, accounting for approximately $1 \%$ of all cases of breast cancer. Less is known about the genetic influences in its development. Male breast cancer has been linked to mutations of the BRCA2 gene in some cases, with the frequency of mutations varying widely (from $4-40 \%$ ) in those series studied. ${ }^{34}$

It has been suggested that there may be other genetic factors that confer a lower absolute risk to the person, but potentially could result in a substantial number of cases within a whole population. ${ }^{5}$ We have already shown that a polymorphism in the CYP17 gene is associated with an increased risk of male breast cancer. ${ }^{6}$

A region within exon 1 of the gene coding for the androgen receptor (located on chromosome Xq11-12) is highly polymorphic and contains a variable number of CAG repeats. The variability of the number of these repeats between different ethnic populations in the USA has been studied. ${ }^{7}$ In vitro studies have shown that a relatively short CAG repeat sequence increases the level of transactivation of the androgen receptor. ${ }^{8}$ The androgen receptor itself binds dihydrotestosterone and therefore is one factor in the regulation of the growth of prostate cells. This may account for the finding that short CAG repeat sequences have been associated with a higher risk of developing prostate cancer. ${ }^{9}{ }^{10}$ Abnormally long sequences of 40 repeats or more are found in patients with X linked spinal and bulbar muscular atrophy (Kennedy's disease). ${ }^{11}$ This disease is associated with gynaecomastia and reduced fertility, suggestive of androgen insensitivity. Mutations of the androgen receptor gene may also result in reduced androgen receptor function and have been found in a few cases of male breast cancer. ${ }^{1213}$

The aim of this study was to investigate whether increased length of the CAG repeat sequence in the androgen receptor gene is associated with the development of male breast cancer.

The selection of male breast cancer cases and controls has previously been described. ${ }^{6}$ Ethical approval for the study was obtained through the Lothian Regional Ethics Committee.

DNA extraction was from whole blood by standard phenol/chloroform extraction. DNA extraction from wax embedded tissue was from $10 \mu \mathrm{m}$ sections incubated at $55^{\circ} \mathrm{C}$ with a lysis buffer and proteinase $\mathrm{K}$.

Using the published sequence, ${ }^{14}$ the following primers were designed (Primer Designer v1.1 (C1990 Educational Software): ARG-F 5'-TGCGCGAAGTGATCCAGA ACC-3', ARG-R 5'-CTCATCCAGGACCAGGTAGCC3'. These generate PCR fragments containing the CAG repeat sequence.

PCR reactions were performed in $50 \mu$ l aliquots, each containing $1 \times$ PCR reaction buffer, $2 \mathrm{mmol} / 1 \mathrm{MgCl}_{2}, 5 \mu \mathrm{l}$ dimethyl sulphoxide, $200 \mu \mathrm{mol} / 1$ deoxynucleoside triphosphates, 20 pmol of each primer, 1 unit of Taq polymerase (Life Technologies ${ }^{\mathrm{TM}}$ ), and approximately $100 \mathrm{ng}$ DNA. The amplification was performed using an OmniGene thermal cycler (Hybaid, UK) under the following conditions: initial denaturation at $94^{\circ} \mathrm{C}$ for three minutes; amplification for 38 cycles, with denaturation at $94^{\circ} \mathrm{C}$ for 45 seconds, annealing at $56^{\circ} \mathrm{C}$ for 45 seconds, and extension at $72^{\circ} \mathrm{C}$ for 45 seconds; final extension at $72^{\circ} \mathrm{C}$ for 10 minutes.

The products were denatured and then run on $6 \%$ polyacrylamide gels with a $10 \mathrm{bp}$ DNA ladder. The products were then ranked in order of length. Three representative products were sent for automated sequencing (DNASHEF, Department of Haematology, Royal Infirmary of Edinburgh) to confirm the number of CAG repeats, and these were used as size standards. The products were then run again, with those thought to be of equal length adjacent to each other in order to check the accuracy of the original estimation of length. A second re-run was then performed to confirm the accuracy of the results.

The lengths of the PCR products obtained varied between $224 \mathrm{bp}$ and $272 \mathrm{bp}$ (corresponding to $14 \mathrm{CAG}$ repeats and 30 CAG repeats, respectively). PCR was unsuccessful with DNA extracted from eight of the archival wax embedded tissue sections.

The distribution of alleles among male breast cancer patients and controls is shown in fig 1 . The median number of CAG repeats in both groups was 23 . There were no statistically significant differences between the two groups (Mann-Whitney test, $\mathrm{p}=0.916$ ).

Three patients showed evidence of two different alleles indicating the presence of two X chromosomes (fig 2). One of these (MBC8) was recorded on the Edinburgh Cytogenetics Register with a diagnosis of Klinefelter's syndrome. The other two patients (MBC42 and MBC 62) had died, but there was no record of clinical suspicion of Klinefelter's syndrome in their hospital case notes. Neither fathered any children. The data were reanalysed following exclusion of these three cases. The median number of CAG repeats for the remaining 53 male breast

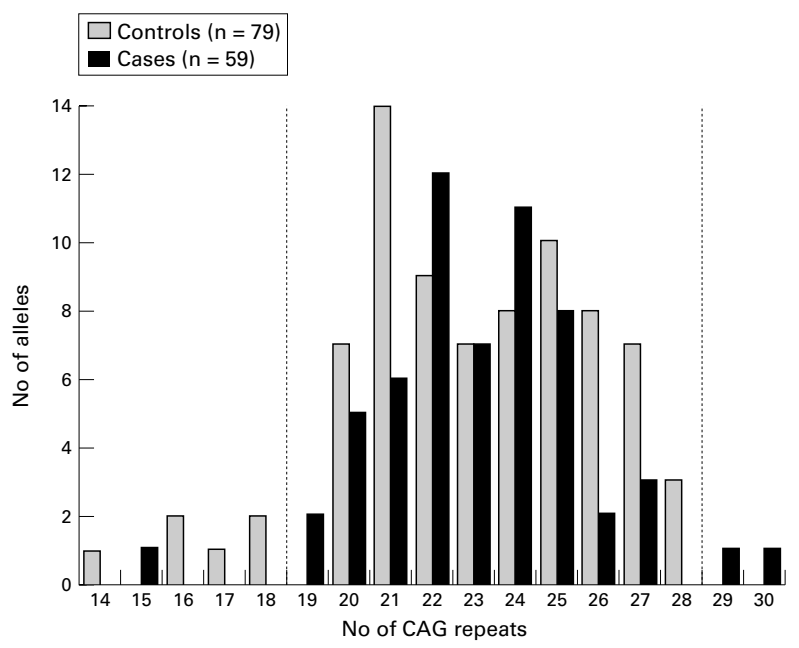

Figure 1 Distribution of $C A G$ repeats in the androgen receptor gene among male breast cancer patients and controls. 


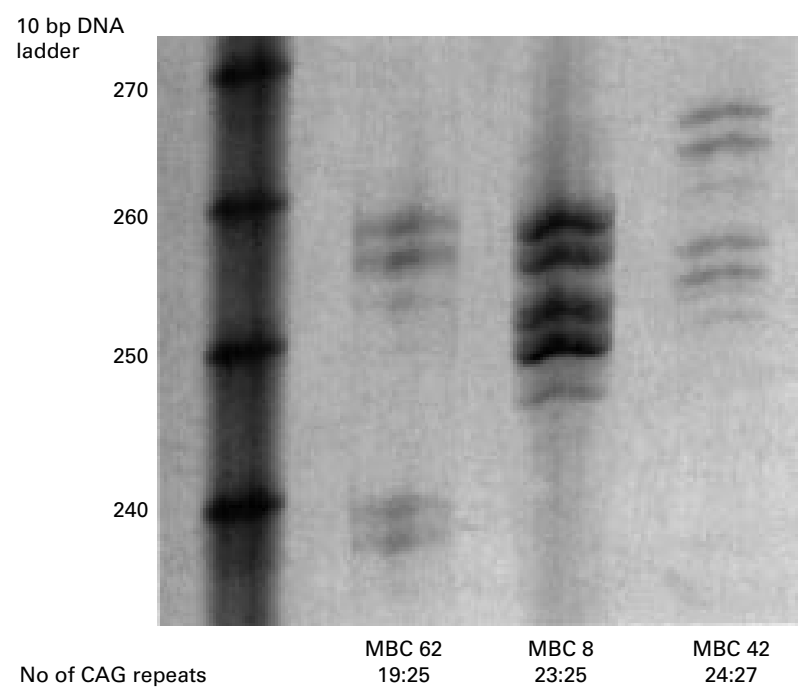

Figure 2 Genotyping of the three male breast cancer patients carrying two different alleles of the androgen receptor gene.

cancer patients was also 23 . There was still no statistically significant difference between cases and controls $(p=0.765)$.

We have not observed any overall difference between the median CAG repeat length of male breast cancer patients and controls. However, no males in the control group had alleles containing more than $28 \mathrm{CAG}$ repeats, whereas two of the male breast cancer patients had alleles with 29 and 30 repeats respectively. Only one of the male breast cancer patients had an allele containing 18 repeats or less, compared to six of the controls. To our knowledge, the length of this CAG repeat has only been studied in one group of male breast cancer patients previously. ${ }^{15}$ There was found to be no significant difference between male breast cancer cases and controls. However, sequences of 30 repeats or more were found only among cases. Our results are consistent with these findings. In addition, it has been recently observed that women who are carriers of $B R C A 1$ mutations are at a significantly increased risk of breast cancer if they carry at least one androgen receptor gene allele with 28 or more CAG repeats. ${ }^{16}$ We believe that a relatively long CAG repeat sequence within the androgen receptor gene may be implicated in a few cases of male breast cancer. Conversely, a short CAG repeat sequence might offer a degree of protection against male breast cancer.

It is well recognised that Klinefelter's syndrome is associated with an increased risk of male breast cancer. ${ }^{17}$ One of the male breast cancer patients in our study was known to have had Klinefelter's syndrome. Our study of the androgen receptor gene has enabled us to identify a further two patients whom we suspect to have had Klinefelter's syndrome.

The findings presented in this study indicate that the CAG repeat sequence within the androgen receptor gene may, in some cases, be one useful molecular marker to identify males at increased risk of developing breast cancer.
Larger studies are required to define the importance of this CAG repeat in male breast cancer further. An international consortium has recently been set up and we have agreed to contribute our data to this.

There is also a GGC repeat sequence within exon 1 of the androgen receptor gene. This might be an interesting area for further study.

We thank the following: Mr R Morris and Dr S Bader for technical advice; Dr T Anderson, Dr A McGregor, Dr I Nawroz, Dr K Ramesar, and Dr A M Lutfy for making available the archival wax embedded tissue sections; Miss G Kerr and the medical records staff in the Department of Clinical Oncology, Western General Hospital, Edinburgh; and staff in the Department of Blood Transfusion Medicine, Royal Infirmary of Edinburgh and in the Department of ENT Medicine, Royal Infirmary of Edinburgh and in the Department of ENT Surgery, City Hospital, Edinburgh for providing some of the control samples.
This work has been funded by grants from the Royal College of Surgeons of
Edinburgh, the Sarah Percy Fund, the Melville Trust for the Care and Cure of Edinburgh, the Sarah Percy Fund,
Cancer, and the Robertson Trust.

IE YOUNG* KM KURIAN* M A F MACKENZIE* I H KUNKLER+ B B COHEN $\ddagger$ MLHOOPER* A $\mathrm{H}$ WYLLIE`S C M STEEL

* Sir Alastair Currie CRC Laboratories, University of Edinburgh Department of Pathology, Molecular Medicine Centre,

Western General Hospital, Crewe Road, Edinburgh EH4 2XU, UK

tDepartment of Clinical Oncology, Western General Hospital, Crewe Road, Edinburgh EH4 2XU, UK

$¥$ School of Biomedical Sciences, Bute Medical Building,

University of St Andrews, St Andrews, Fife KY16 9TS, UK

ऽDepartment of Pathology, University of Cambridge, Tennis Court Road, Cambridge CB2 1QP, UK

1 Miki Y, Swensen J, Shattuck-Eidens D, et al. A strong candidate for the breast and ovarian cancer susceptibility gene BRCA1. Science 1994;266:6671.

2 Wooster R, Bignell G, Lancaster J, et al. Identification of the breast cancer susceptibility gene BRCA2. Nature 1995;378:789-92.

3 Friedman IS, Gayther SA, Kurosaki T, et al. Mutation analysis of BRCA1 and BRCA2 in a male breast cancer population. Am 7 Hum Genet 1997;60: 313-19.

4 Thorlacius S, Olafsdottir G, Tryggvadottir L, et al. A single BRCA2 mutation in male and female breast cancer families from Iceland with varied cancer phenotypes. Nat Genet 1996;13:117-19.

5 Feigelson HS, Ross RK, Yu MC, Coetzee GA, Reichardt JKV, Henderson $\mathrm{BE}$. Genetic susceptibility to cancer from exogenous and endogenous exposures. F Cell Biochem 1996;25(suppl):15-22.

6 Young IE, Kurian KM, Annink C, et al. A polymorphism in the CYP17 gene is associated with male breast cancer. Br F Cancer 1999;81:141-3.

7 Edwards AL, Hammond HA, Jin L, Caskey CT, Chakraborty R. Genetic variation at five trimeric and tetrameric tandem repeat loci in four human population groups. Genomics 1992;12:241-53.

8 Chamberlain NL, Driver ED, Miesfeld RL. The length and location of CAG trinucleotide repeats in the androgen receptor N-terminal domain affect transactivation function. Nucleic Acids Res 1994;22:3181-6.

9 Stanford JL, Just JJ, Gibbs M, et al. Polymorphic repeats in the androgen receptor gene: molecular markers of prostate cancer risk. Cancer Res 1997; 57:1194-8.

10 Giovannucci E, Stampfer MJ, Krithivas K, et al. The CAG repeat within the androgen receptor gene and its relationship to prostate cancer. Proc Natl Acad Sci USA 1997:94:3320-3.

11 LaSpada AR, Wilson EM, Lubahn DB, Harding AE, Fishbeck KH. Androgen receptor gene mutations in X-linked spinal muscular atrophy. Nature 1991;352:77-9.

12 Wooster R, Mangion J, Eeles R, et al. A germline mutation in the androgen receptor gene in two brothers with breast cancer and Reifenstein syndrome. Nat Genet 1992;2:132-4.

13 Lobaccaro JM, Lumbroso S, Belon C, et al. Male breast cancer and the androgen receptor gene. Nat Genet 1993;5:109-10.

14 Available from URL: http://www.uwcm.ac.uk

15 Haraldsson K, Loman N, Zhang QX, Johannsson O, Olsson H, Borg A. BRCA2 germ-line mutations are frequent in male breast cancer patients without a family history of the disease. Cancer Res 1998;58:1367-71.

16 Rebbeck TR, Kantoff PW, Krithivas K, et al. Modification of BRCA1associated breast cancer risk by the polymorphic androgen-receptor CAG repeat. Am f Hum Genet 1999;64:1371-7.

17 Jackson AW, Muldal S, Ockey CH, O'Connor PJ. Carcinoma of the male breast in association with the Klinefelter syndrome. BM7 1965;i:223-5. 


\section{Deletion and duplication of the adenomatous polyposis coli gene resulting from an interchromosomal insertion involving 5(q22q23.3) in the father}

EDITOR-Chromosomal rearrangements occur at a low frequency in the general population and chromosomal insertions occur at an estimated frequency of 1 in 5000 newborn infants. ${ }^{1}$ Adjacent segregation of interchromosomal insertions results in a deletion or duplication of the inserted segment or more complicated imbalances through a recombination event at meiosis. In the case presented here, a balanced interchromosomal insertion between chromosomes 5 and 10, 46,XY,dir ins(10;5)(q25;q22q23.3), was carried by the father. Theoretically this insertion involves less than $1 \%$ of the haploid autosomal length and therefore a fetus with either a duplication or deletion is likely to be viable unless there are essential genes in this segment that are deleterious in an aneuploid conceptus. Generally deletions are more deleterious than duplications and there are few published cases where the clinical features of a duplication and deletion for the same chromosomal region have been described within the same family. ${ }^{23}$

In this paper we report four cases of a 5 q22q23.3 deletion and one case of a duplication for the same region which includes the $A P C$ gene. All of the aneuploid offspring were within the same generation and the clinical features associated with $5 \mathrm{q} 22 \mathrm{q} 23.3$ deletion with a similar genetic background will be compared with published cases.

Lymphocytes were cultured by standard methods including semi-synchronisation with thymidine and preparations were analysed using $\mathrm{G}$ banding. ${ }^{4}$ Fluorescence in situ hybridisation (FISH) of the chromosome preparations involved YAC probe $37 \mathrm{HG} 4$ containing a $2.3 \mathrm{~kb}$ fragment of cDNA from the $A P C$ gene which recognises an $M s p \mathrm{I}$ polymorphism. ${ }^{5}$ The $A P C$ gene has been localised to the subband $5 \mathrm{q} 22.1 .^{5}$ Standard FISH procedures were used and have been published elsewhere. ${ }^{6}$ FISH images were viewed using computer enhanced image analysis systems (Vysis).

The family were investigated on the birth of the proband. The parents were first cousins of Asian origin and the mother did not speak any English. At the birth of the sec- ond child the father was 34 and the mother 21 years of age. They have three clinically normal children (first, third, and eighth pregnancies, II.1, II.3, and II.8) although the chromosome constitution of one of them is unknown (II.1). However, the remaining five pregnancies resulted in chromosomally abnormal offspring (fig 1).The parents had genetic counselling after the birth of their second child (case I, II.2) and further follow up of family members was declined.

In case 1 (II.2) the pregnancy was uneventful and the infant was delivered at term. At birth his Apgar score was 3 at one minute, 6 at five minutes, and 9 at 10 minutes. Intubation failed as the vocal cords could not be visualised owing to the malformed head and neck. His birth weight was $1860 \mathrm{~g}$ and head circumference $34 \mathrm{~cm}$. Physical examination showed cleft palate, micro-osmia, anteverted nostrils, micrognathia, downward slanting palpebral fissures, talipes equinovarus, polydactyly (nine toes on the right foot), low set ears, bilateral VII cranial nerve palsy, and ulnar deviation of the fingers (fig 2). He was also tachypnoeic from birth with chest wall recession and irregular respiratory effort. Chest $x$ ray showed clear lungs. Septic and TORCH screen were normal. Arterial blood gases showed a mild metabolic acidosis. ECG was normal. The tachypnoea remained unexplained. The proband was initially nursed in oxygen but later tolerated air. The child showed restricted movement of all limbs. At 16 days an $x$ ray showed a fractured right humerus with callous surrounding a fracture of the right clavicle. No pathological cause was found. He was extremely irritable, with a paucity of spontaneous movement and inability to feed without a nasogastric tube.

On day 23 he became deeply cyanosed with breathing even more laboured than previously and died suddenly the same day. Necropsy was declined on religious grounds.

The patient's karyotype showed a deleted chromosome 5, 46,XY,del(5)(q22q23.3). Investigation of the parents' blood indicated that the mother had a normal female karyotype. However, the father had an interchromosomal insertion of the $5 \mathrm{q} 22 \mathrm{q} 23.3$ segment into chromosome 10 , 46,XY,dir ins (10;5)(q25;q22q23.3) (fig 3).

The proband's karyotype was therefore 46,XY,der(5)dir ins $(10 ; 5)$ (q25;q22q23.3)pat.

With case 2 (II.3, fig 1), the mother had an amniocentesis at 17 weeks' gestation; a normal male chromosome constitution was reported and the pregnancy continued to term. The baby had no dysmorphic features at birth and examination at 5 years of age showed a unilateral simian

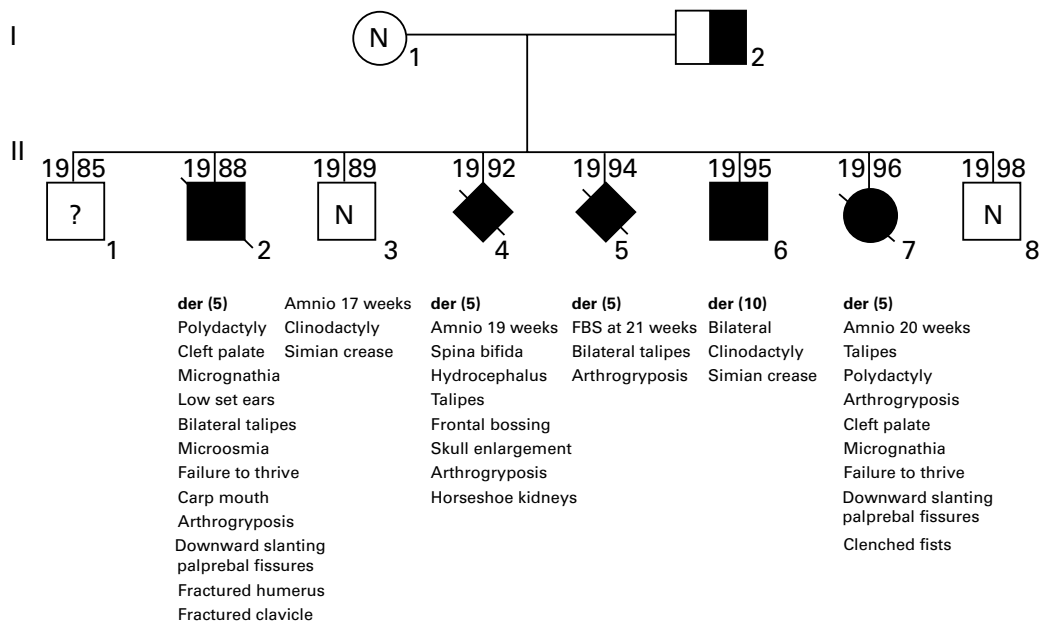

Figure 1 Diagrammatic summary of clinical features in the family. The father (I.2) carries the interchromosomal insertion. N=normal karyotype. 

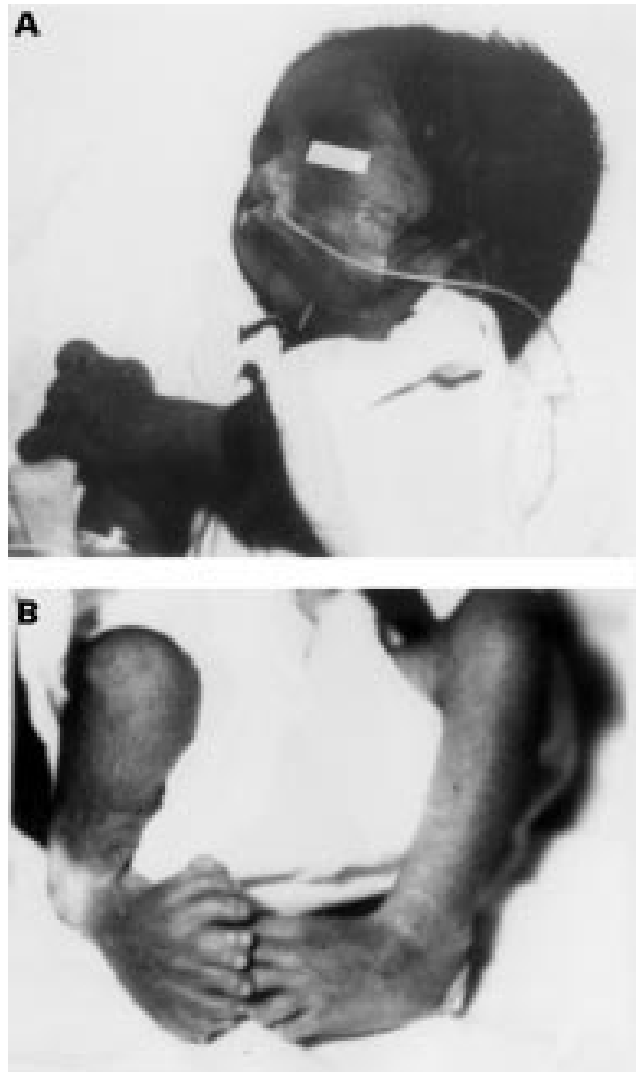

Figure 2 (A) Case II.2 at birth and (B) polydactyly and talipes of the right foot. (All photographs reproduced with permission.)

crease, clinodactyly, and a right undescended testis. An orchidopexy was later performed.

With case 3 (II.4, fig 1), the parents initially declined prenatal diagnosis but ultrasound scan at 19 weeks' gestation showed hydrocephalus and lumbosacral spina bifida. The pregnancy was terminated at 22 weeks' gestation after cytogenetic analysis of amniotic cells showed an abnormal karyotype, 46,XY,der(5)dir ins(10;5)(q25;q22q23.3)pat. At necropsy the fetus weighed $280 \mathrm{~g}$, crown-rump length was $17.0 \mathrm{~cm}$, and head circumference $24.5 \mathrm{~cm}$. External examination showed frontal bossing and a large head. The lumbar meningomyelocele was confirmed but the fetus also had borderline hydrocephalus, a horseshoe kidney, and bilateral talipes. No heart, lung, or brain abnormalities were evident, but the lung, adrenal, and thymus showed congestion.

With case 4 (II.5, fig 1), the mother presented in the second trimester and ultrasound scan at $21+4$ weeks' gestation showed a normal sized fetus for gestation. The head circumference was $18.6 \mathrm{~cm}, \mathrm{BPD} 53 \mathrm{~cm}$, and the heart, spine, and diaphragm appeared normal. However, polydactyly (six toes on each foot), bilateral talipes, and arthrogryposis of the elbows and fingers were evident, and a pterygium at each elbow was suspected on ultrasound. A fetal blood sample was taken for cytogenetic studies and analysis showed a male fetus with the der(5). FISH studies using the APC probe showed only one signal in all divisions examined, 46,XY,der(5)dir ins(10;5)(q25;q22q23.3).ish der(5)dir ins(q25;q22q23.3)(37HG4-) (fig 4). The parents elected to terminate the pregnancy.

With case 5 (II.6, fig 1), the mother presented in the second trimester and an ultrasound scan at 19 weeks' gestation was normal. Prenatal diagnosis was declined. The male child, born at term weighing $2700 \mathrm{~g}$, was clinically normal on initial assessment. Blood was sent for karyotyping at birth by the paediatricians because of the previous family history.
Neonatal blood showed a male child with a duplication of 5q22q23.3, 46,XY,der(10)dir ins(10;5)(q25;q22q23.3)pat (fig 5). FISH using the APC probe showed three signals on blood interphase cells, nuc ish 5q22.1(37HG4x3). Detailed examination of the child after cytogenetic investigation showed a third fontanelle, bilateral clinodactyly, a unilateral simian crease, and an undescended left testis. No other dysmorphic features were evident. The child was developmentally normal at 2 years of age.

In the pregnancy of case 6 (II.7, fig 1), the mother underwent initial ultrasound examination at 20 weeks' gestation. This showed talipes, polydactyly, and arthrogryposis. Cytogenetic analysis of the amniotic fluid showed a female fetus with a $\operatorname{der}(5), \quad 46, \mathrm{XX}, \operatorname{der}(5) \operatorname{dir}$ ins $(10 ; 5)$ (q25;q22q23.3)pat. The parents elected to continue the pregnancy and a dysmorphic child was born at term. The child had a cleft palate, downward slanting palpebral fissures, clenched fists, restricted hip movement, polydactyly of the right foot (six toes), hirsutism, talipes, micrognathia, and low set ears (fig 6). She also had similar respiratory difficulties to case 1 . Examination at 3 months showed further dysmorphism including developmental delay, glossoptosis, barrel shaped chest, abnormal lumbosacral spine, increased tone, simple left ear, unilateral accessory auricle, and epicanthic folds. The child had to be fed by nasal tube as she was unable to feed orally. The child died at 11 months of age and necropsy was declined.

With case 7 (II.8, fig 1), the mother declined prenatal diagnosis but serial ultrasound appeared normal and growth was satisfactory. The pregnancy and birth were uncomplicated. A male child was born at term and the Apgar scores were 8 at one minute and 9 at five minutes. There were no dysmorphic features at 8 weeks of age except unilateral clinodactyly which was also present in the mother. The karyotype was normal, 46,XY.

The oldest male child (II.1) has not been karyotyped but his growth and development are normal.

Interchromosomal insertions are individually rare events and in this family both a deletion and duplication of the inserted region were viable. Interchromosomal insertions involve three break rearrangements and theoretically such insertions can lead to aneusomy via two mechanisms, segregation or recombination. However, observed aneusomies have mostly resulted from segregation ${ }^{7}$ and only exceptionally from recombination. ${ }^{8}$ In this family adjacent 1 segregation of the insertion has provided a unique study of four monosomy 5q22q23.3 offspring with a similar genetic background and a clinically normal child with a duplication of $5 \mathrm{q} 22 \mathrm{q} 23.1$. There has been one other reported case of a $(10 ; 5)$ interchromosomal insertion and this gave rise to an infant with duplication of a more proximal region of $5 \mathrm{q}(\mathrm{q} 13 \mathrm{q} 22) .^{9}$

Of the previous 27 cases where a deletion of 5q13-31 has been published, 24 have arisen de novo ${ }^{11}{ }^{13-31}$ and three were recombinants from an intrachromosomal insertion. ${ }^{10}{ }^{12}$ As far as we are aware this is the first reported case of deletion $5 \mathrm{q}$ resulting from segregation of an interchromosomal insertion in the parent.

Earlier publications have described either a distal $5 \mathrm{q} 22$ or proximal deletion of $5 \mathrm{q} 13$ because of the similarity of the bands in 5q. Consistent clinical features associated with deletion of distal 5q22-q31 include developmental delay, low birth weight, failure to thrive, decreased fetal movement, polyhydramnios, camptodactyly, small mouth, high arched palate, micrognathia, hypertelorism, downward slanting palprebal fissures, short stature, head circumference above $35 \mathrm{~cm}$, frontal bossing, epicanthic folds, depressed nasal bridge, anteverted nostrils, low set ears, short neck, cleft palate (50\% cases), head and heart abnormalities ( $50 \%$ cases), talipes, simian crease, and 


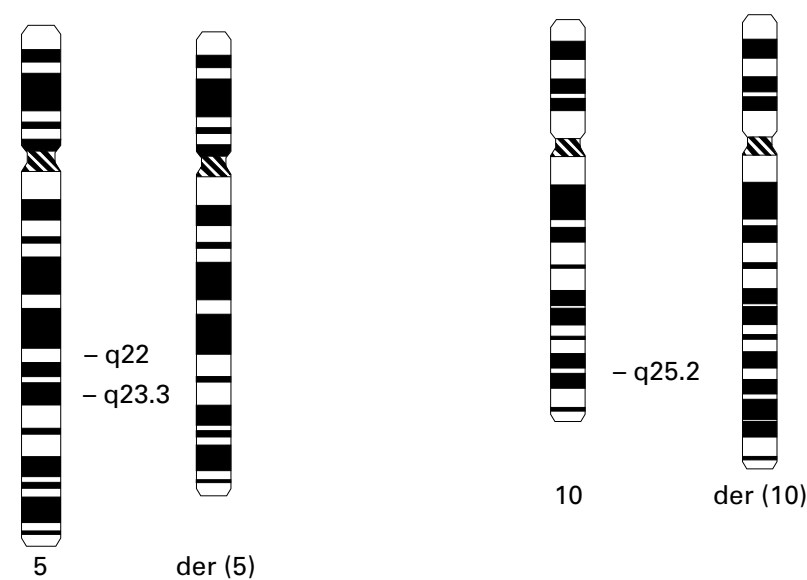

Figure 3 A diagrammatic representation of the interchromosomal direct insertion between chromosomes 5 and 10 in the father.

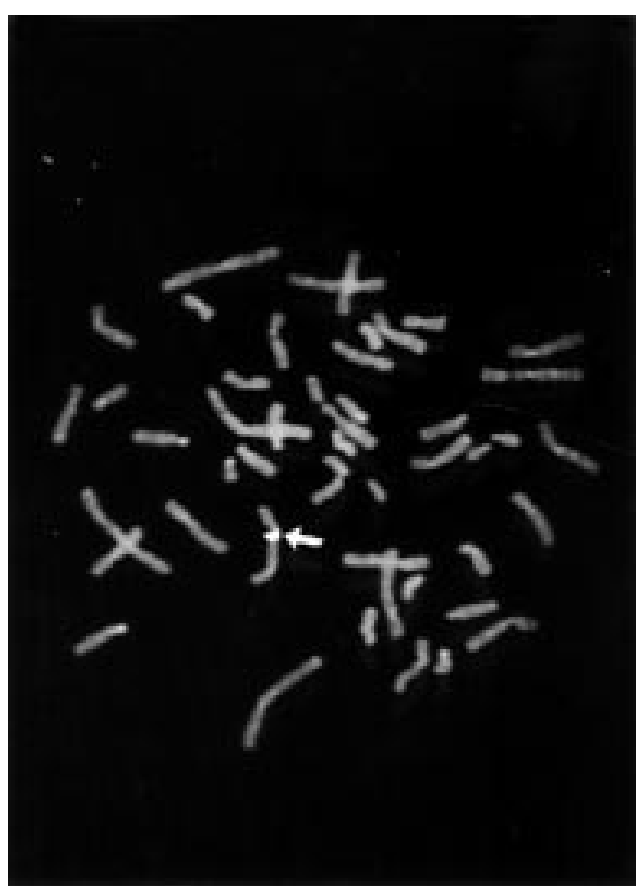

Figure 4 FISH using YAC probe 37HG4 showing a single signal (arrowed) in a metaphase from II. 2.

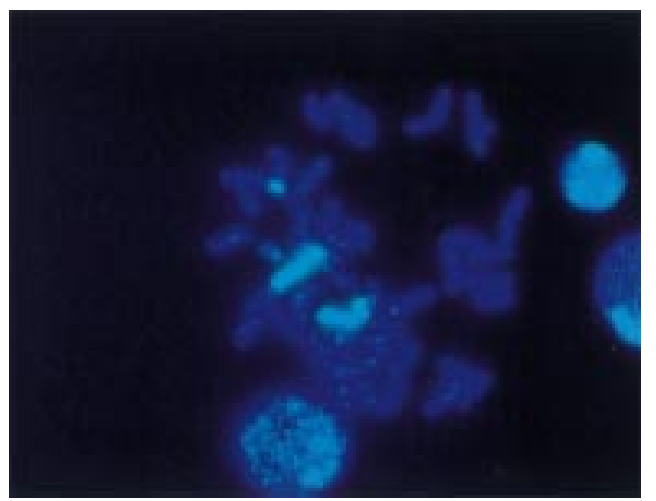

Figure 5 FISH using chromosome 5 paint showing a duplication of chromosome 5 material inserted into chromosome 10.

mental and motor retardation. Other clinical features less frequently observed were dislocation of the hips $(28 \%)$, thin upper lip (28\%), carp shaped mouth $(28 \%)$, and repeated respiratory and urinary infections $(43 \%){ }^{32}$ The four cases described here all had talipes and arthrogryposis while case 1 also had low birth weight, failure to thrive, depressed nasal bridge, micro-osmia, anteverted nostrils, low set ears, micrognathia, carp shaped mouth, cleft palate, downward slanting palpebral fissures, single simian crease, short neck, mental retardation and recurrent respiratory infections. Case 3 had skull enlargement, frontal bossing, and low set ears while case 6 had cleft palate, downward slanting palprebal fissures, low set ears, and respiratory problems. Only three published cases have a similar breakpoint (5q22q23.3) to the deletion cases described here and two had mental retardation, multiple epidermoid cysts, long midface, and APC. ${ }^{12}$ A third case ${ }^{19}$ described an adult with a bossed, high forehead, long philtrum, high arched palate, joint laxity, long fingers, and APC. Interstitial deletions of $5 q 22$ have been reported in adults with polyposis coli but as the cases described here have a larger deletion involving 5q23.3 they are unlikely to survive to adulthood when APC would be evident.

Several consistent features between the cases presented in this paper and previously published cases of a deletion of $5 \mathrm{q} 22 \mathrm{q} 23.3$ include arthrogryposis and talipes, suggesting that some limb development genes as well as $A P C$ are localised to this chromosomal region. One of the malformations displayed by cases 1,4 , and 6 was polydactyly. In view of the proposed role of $A P C$ in some forms of apoptosis and the function of the Drosophila homologues of $A P C, \beta$-catenin, and $G S K 3 \beta$ in segment polarity and other aspects of cell fate, ${ }^{33}$ the finding of polydactyly in this family is of interest. Mice carrying the $A p c$ mutation have been seen to display digital abnormalities, but polydactyly is not a frequent finding in patients with deletions of the $A P C$ locus and may therefore be a consequence of genes other than $A P C$ in the family presented here. $^{34}$

Reports of duplication for the distal 5q segment are rare, as many are a result of an unbalanced segregation of a translocation and are also deleted for another chromosome. Case 5 and that of Gilgenkrantz et $a l^{9}$ are unique in that they are both the result of familial insertion. Three patients with a duplication of $5 \mathrm{q} 22 \mathrm{q} 23.3$ have been reported and were all clinically dysmorphic with developmental delay. Features included microcephaly, psychomotor and mental retardation, small ears, strabismus, sloping, enlarged forehead, prominent nasal bridge, small chin, disproportionately long arms, esotropia, spasticity, and episodes of self mutilation. ${ }^{32}$ Patients with a more distal duplication have features which include low birth weight, brachycephaly, clinodactyly, facial anomalies with protruding nose, and enlarged forehead. ${ }^{32}$ Case 5 is unusual in that duplication of a segment of $5 \mathrm{q} 22 \mathrm{q} 23.3$ incorporating a known gene has occurred without obvious 


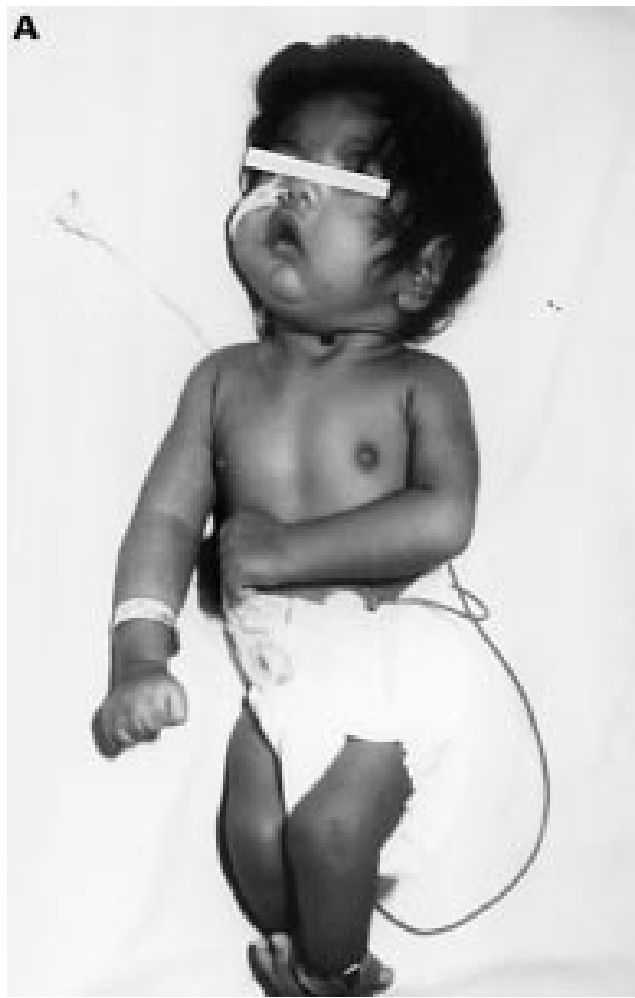

Figure 6 (A) Case II.7 at birth and (B) polydactyly and talipes of the feet.

phenotypic effect at 4 years of age. The child had a simian crease, clinodactyly, and undescended testis, but these features are also found in normal subjects; this is supported by the presence of the same phenotype in one of the sibs (case 2) who had a normal karyotype. The presence of an extra copy of $A P C$ could have a longer term effect especially in the colorectum. This child is effectively a natural experiment and if no phenotypic abnormalities of the colorectum occur then this would have implications for the safety of gene therapy for FAP in that an extra copy of $A P C$ in a colonocyte is not harmful.

Ultrasonography is becoming an increasingly more useful tool for detecting pregnancies at risk for a chromosome abnormality or genetic disorders. However, for couples with a known chromosome rearrangement, prenatal diagnosis is essential if a viable offspring with an abnormal clinical outcome is likely. It is also recommended that cases of clinically normal subjects with unbalanced karyotypes are published so that an informed decision can be made by parents prenatally when a similar rearrangement is identified. This paper presents such an example, as duplication of $5 \mathrm{q} 22 \mathrm{q} 23.3$ may not result in clinical abnormality.

The authors would like to thank Simon Roth who referred the proband to the Cytogenetics Department and Helwyn Morgan for referring subsequent prenatal samples. The ideogram was produced using Applied Imaging software.

R J HASTINGS* E C SVENNEVIK* B SETTERFIELD* D WELLS $\dagger$ J D A DELHANTY* $†$ H MACKINNON

${ }^{\star}$ Clinical Cytogenetics, The Galton Laboratory, University College London, Wolfson House, 4 Stephenson Way, London NW1 2HE, UK tThe Galton Laboratory, University College London, Wolfson House, 4 Stephenson Way, London NW1 2HE, UK

$\neq$ Paediatric Department, Whittington Hospital, St Mary’s Wing, Highgate Hill, London N19 5NF, UK

Correspondence to:

Dr Hastings

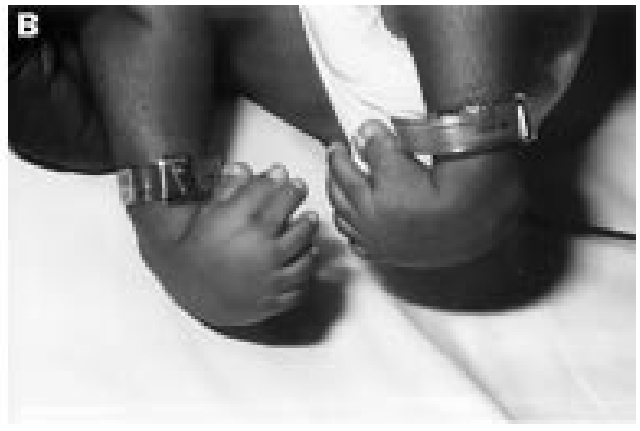

1 De Arce MA, Law E, Martin L, Masterson JG. A case of inverted insertion De Arce MA, Law E, Martin L, Masterson JG. A case of invert

2 Beemer FA, de France HF, Rosina-Angelista IJM, Gerards LJ, Cats BP, Guyt R. Familial partial monosomy $5 \mathrm{p}$ and trisomy $5 \mathrm{q}$; three cases due to paternal pericentric inversion 5 (p151q333). Clin Genet 1984;26:209-15.

3 Lazjuk GI, Lurie IW, Kirillova IA, et al. Partial trisomy $5 \mathrm{q}$ and partial monosomy $5 \mathrm{q}$ within the same family. Clin Genet 1985;28:122-9.

4 Rooney DE, Czepulkowski BH. Human cytogenetics: a practical approach. Vol II. Oxford: IRL Press, 1992

5 Kinzler KW, Nilbert MC, Su LK, et al. Identification of FAP locus genes from chromosome 5q21. Science 1991;253:661-5.

6 Pinkel D, Straume T, Gray JW. Cytogenetic analysis using quantitative, high sensitivity fluorescence hybridisation. Proc Natl Acad Sci USA 1986; 83:2934-8

7 Hastings R, Hamer B, Roth S, Lucas M. Partial trisomy 4p resulting from a balanced intrachromosomal insertion, 4(q313p14p16). Clin Genet 1990; 38:121-5.

8 Jalbert P, Albert HJ, Sele B, et al. Partial trisomy for long arms of chromosome no 5 due to insertion and further "aneusomie de recombination". $\mathcal{F}$ Med Genet 1975;12:418-23.

9 Gilgenkrantz S, Dulucq P, Bresson JL, Gouget A, Pernot C, Gregoire MJ. Partial proximal trisomy of the long arm of chromosome $5(\mathrm{q} 13 \rightarrow \mathrm{q} 22)$ resulting from maternal insertion dir ins $(10 ; 5), 7$ Med Gent 1981;18:465-9.

10 Barber JCK, Ellish, FH, Bowles LV, et al. Adenomatous polyposis coli and a cytogenetic deletion of chromosome 5 resulting from a maternal intrachromosomal insertion. F Med Genet 1994;31:312-16.

11 Centerwall WR, Parslow M, Costello J. Interstitial deletion in the long arm of chromosome 5: a cytogenetic syndrome. Am f Hum Genet 1978;30:75A.

12 Cross I, Delhanty J, Chapman P, et al. An intrachromosomal insertion causing 5q22 deletion and familial polyposis coli in two generations. F Med Genet 1992;29:175-80.

13 Dudin G, Alexander D, Talj F, Deeb M, Musallum S, Der Kaloustian VM. Interstitial deletion of band q12 of chromosome 5. Clin Genet 1984:25:455-8.

14 Erdtman B, Salzano FM, Mattevi MS. Chromosome studies in patients with congenital malformations and mental retardation. Hum Genet 1975;26: 297-306.

15 Felding I, Krissofferson U. A child with interstitial deletion of chromosome no 5. Heredity 1980;93:337-9.

16 Fukada T, Fukushima Y, Kuroki Y. A case of interstitial deletion of the long arm of chromosome 5: 46,XX,del(5)(q15q22). Fpn f Hum Genet 1984;29:63-7.

17 Harprecht-Beato W, Kaiser WP, Steuber E, Reinhard W. Interstitial deletion of the long arm of chromosome 5. Clin Genet 1983;23:167-71.

18 Herrera L, Kakati S, Gibas L, Pietrzak E, Sandberg AA. Brief clinical report: Gardner syndrome in a man with interstitial deletion of 5q. Am F Med Genet 1986;25:473-6.

19 Hodgson SV, Coonar AS, Hanson PJV, et al. Two cases of 5q deletions in patients with familial adenomatous polyposis: possible links with Caroli disease. F Med Genet 1993;30:369-75.

20 Kucerova M, Polivkova Z. 46,XX, $\operatorname{del}(5)$ (pter to q15::q22 to qter). In: Borgaonkar DS, Lillard DR, eds Repository of chromosomal variants and anomalies in man. Fifth listing. Denton: North Texas University, 1978:56.

21 Lindenbaum RH, Butler LJ. Child with multiple anomalies and a group B(4-5) long arm deletion (Bq-). Arch Dis Child 1971;46:99-101.

22 Lindgren V, Bryke CR, Ozcelik T, Yang-Feng TL, Francke U. Phenotypic, cytogenetic and molecular studies of three patients with constitutional deletions of chromosome 5 in the region of the gene for familial adenomatous polyposis. Am f Hum Genet 1992;50:988-97. 
23 Ohdo S, Madokoro H, Hayakawa K. Interstital deletion of the long arm of chromosome 5: 46,XX, del(5)(q13q22). 7 Med Genet 1982;19:479.

24 Palmer CG, Coburn S, Leikoff E. 46, XY, del (5)(pter to q21::q23 to qter). In: Borgaonkar DS. Lillard DR, eds. Repository of chromosomal variants and In: Borgaonkar DS. Lillard DR, eds. Repository of chromosomal variants and

25 Pescia GA, Gaide C, Juillard E. Syndrome dysmorphique debilite mentale et deletion interstitielle des bras longs d'un chromosome 5. Ann Genet 1978; 21:161-3

26 Rodewald A, Zankl M, Sitzmann FC, Zang KD. Interstitial de novo deletion of the long arm of chromosome 5: mapping of $5 \mathrm{q}$ bands associated with particular malformations. Clin Genet 1982;22:226-30.

27 Rivera H, Rolan A, Sanchez-Corona J, Cantu JM. De novo t $(4 ; 5)$ (q3100; q2200) with del (5) (q1500q2200). Tentative delineation of a 5q monosomy syndrome and assignment of critical segment. Clin Genet 1985;27:105-109.

28 Rivera H, Garcia-Esquivel L, Moller M, Cantu JM. Constitutional del (5)(q23.3q31.1). Ann Genet 1987;30:91-3.
29 Rivera H, Simi P, Rossi S, Pardeli L, Di Paolo CM. A constitutional 5q23 deletion. 7 Med Genet 1990;27:267-8.

30 Silengo MC, Luzzatti L, Centerwall W, Costello JM, Parslow M. Interstitial deletion of the long arm of chromosome no 5 in two unrelated children with congenital anomalies and mental retardation. Clin Genet 1981;19:17480.

31 Stoll C, Levy JM, Roth MP. Interstitial deletion of the long arm of chromosome 5 in a deformed boy: 46,XY, del(5)(q13q15). F Med Genet 1980;17: 486-7.

32 Peifer $M$, Sweeton D, Casey $M$, Weischaus $E$. Wingless signal and Zeste-white 3 kinase trigger opposing changes in the intracellular distribution of Armadillo. Development 1994;120:369-80.

33 Schinzel A. In: Baraitser M, Winter RM, eds. The human cytogenetics database. Oxford: Oxford University Press, 1996.

34 Wells $\mathrm{D}$. Mutation analysis of the adenomatous polyposis coli gene. $\mathrm{PhD}$ thesis, University of London, 1998:198-207.

f Med Genet 2000;37:145

\section{Hypoparathyroidism, retarded growth and development, and dysmorphism or Sanjad-Sakati syndrome: an Arab disease reminiscent of Kenny-Caffey syndrome}

EDITOR-In the December 1998 issue of fournal of Medical Genetics, four letters discussed whether or not KennyCaffey syndrome (KCS) is a part of CATCH 22. ${ }^{1-4}$ These were based on a report of four Bedouin sibs with an unusual form of KCS that includes the additional features of marked IUGR, severe psychomotor retardation, and microcephaly. Two of the affected sibs and their phenotypically normal mother were found to have microdeletion $22 q 11 .^{5}$ The same authors subsequently suggested that this entity represents the Arab variant of KCS and because of some clinical resemblance to DiGeorge syndrome (DGS) they suggested that the phenotype is the result of $22 \mathrm{q} 11$ microdeletion or some abnormality of chromosome $10 \mathrm{p}$ where a second locus for DGS lies. ${ }^{6}$

This entity was originally described by Sanjad et $a l^{7}$ in 1988 and 1991 as a new syndrome consisting of congenital hypoparathyroidism, seizures, growth and developmental retardation, and dysmorphic features in a group of Arab children of consanguineous parents. Several other reports followed. ${ }^{9-14}$ All were Arabs, particularly Bedouin, with several sets of multiple affected sibs. The children have recognisable identical facies with deep set eyes, depressed nasal bridge with a beaked nose, long philtrum, thin upper lip, micrognathia, and large, floppy ear lobes. Medullary stenosis and other skeletal defects were found in most of them. This, together with the hypocalcaemia, hyperphosphataemia, and low concentration of immunoreactive parathyroid hormone in some of them, makes the phenotype similar to KCS. Recently the syndrome was localised to 1q42-43 by three independent groups. ${ }^{15-17}$ Although they have a similar phenotype, different locus names have been given, namely $H R D$ for hypoparathyroidism, retarded growth and development, and dysmorphism, ${ }^{14} \mathrm{KCS}$ for autosomal recessive KCS, ${ }^{15}$ and SSS for Sanjad-Sakati syndrome. ${ }^{17}$ The name of the syndrome in OMIM is hypoparathyroidism-retardationdysmorphism and is given the number 241410 with autosomal recessive inheritance considered certain. The acronym Sanjad-Sakati syndrome is shown as an alternative.
It is also listed among the Arab diseases in our text book Genetic disorders among Arab populations. ${ }^{18}$

With regard to the family with $22 \mathrm{q} 11$ microdeletion, the association is probably fortuitous or as a remote possibility it might be the cause in a subset of patients with this Arab disease. This issue should be easily resolved at the molecular level.

I believe that it is important for us (practitioners and scientists) to decide on one term for this disorder. For convenience and in order to credit the original authors, I suggest the acronym "Sanjad-Sakati" for the syndrome and $H R D$ for the locus, an abbreviation which refers to the components of the syndrome.

AHMAD S TEEBI

Division of Clinical Genetics, The Hospital for Sick Children and University of Toronto, 555 University Avenue, Toronto, Ontario M5G

$1 X 8$, Canada

1 Yorifuii T, Muroi J, Uematsu A. Kenny-Caffey syndrome without the CATCH 22 deletion. $\mathcal{F}$ Med Genet 1998;35:1054

2 Goodship J. Kenny-Caffey syndrome is part of the CATCH 22 haploinsufficiency cluster. F Med Genet 1998;35:1054.

3 Kirk J. Kenny-Caffey syndrome is part of the CATCH 22 haploinsufficiency cluster. F Med Genet 1998;35:1054.

4 Sabry MA, Zaki M, Shaltout A. Genotypic/phenotypic heterogeneity of Kenny-Caffey syndrome. $\mathcal{F}$ Med Genet 1998;35:1054-5.

5 Sabry MA, Zaki M, Abul Hassan SJ, et al. Kenny-Caffey syndrome is part of the CATCH 22 haploinsufficiency cluster. F Med Genet 1998;35:31-6.

6 Sabry MA, Shaltout A, Zaki M, et al. Kenny-Caffey syndrome: an Arab variant. Am f Hum Genet Suppl 1998;63:A118.

7 Sanjad S, Sakati N, Abu-Osba Y. Congenital hypoparathyroidism with dysmorphic features: a new syndrome. Pediatr Res 1998;23:A419.

8 Sanjad SA, Sakati NA, Abu-Osba YK, Kaddora R, Milner RDG. A new sydrome of congenital hypoparathyrodism, seizure, growth failure and dysmorphic features. Arch Dis Child 1991;66:193-6.

9 Richardson RJ, Kirk JMW. Short stature, mental retardation and hypoparathyroidism: a new syndrome. $尹$ M Med Genet 1990;65:1113-17.

10 Kalam MA, Hafeez W. Congenital hypoparathyroidism, seizure, extreme Kalam MA, Hafeez W. Congenital hypoparathyroidism, seizure, extreme
growth failure with developmental delay and dysmorphic features-another growth failure with developmental delay and dysmorph
case of this new syndrome. Clin Genet 1992;42:110-13.

11 Marsden D, Nyhan Wl, Sakati NA. Syndrome of hypoparathyroidism, growth hormone dificulty and multiple minor anomalies. Am 7 Med Genet 1994;52:334-8.

12 Hershkovitz E, Shaltitin S, Levy J, et al. The new syndrome of congenital hypoparathyroidism associated with dysmorphism, growth retardation, and developmental delay: a report of 6 patients. Israel f Med Sci 1995;31:293-7.

13 Khan KTS, Uma R, Usha R, et al. Kenny-Caffey syndrome in six bedouin sibships: autosomal recessive inheritance confirmed. Am $\mathcal{F}$ Med Genet 1997;69:126-32.

14 Al-Gazali LI, Dawodu A. The syndrome of hypoparathyroidism, severe growth failure, developmental delay and distinctive facies. Clin Dysmorphol 1997; 6:233-7.

15 Parvari R. Hershkovitz E, Kanis A, et al. Homozygosity and linkage disequilibrium mapping of the syndrome of congenital hypoparathyroidism, librium mapping of the syndrome of congenital hypoparathyroidism,
growth and mental retardation, and dysmorphism to a 1-cM interval on growth and mental retardation, and dysmorphism to
chromosome 1q42-3 Am f Hum Genet 1998;63:163-9.

16 Gelb BD, Khan KTS, Diaz GA. The autosomal recessive Kenny-Caffey syndrome locus maps to chromosome 1q42-43. Am f Hum Genet Suppl 1998;63:A290.

17 Ali F, Diaz GA, Sakati N, et al. Localization of the gene for the Sanjad-Sakati syndrome to 1q43. Am ₹ Hum Genet Suppl 1998;63:A279.

18 Teebi AS. Introduction. In: Teebi AS, Farag TI, eds. Genetic disorders among Arab populations. Oxford: Oxford University Press, 1997:1-26. 
Tandem duplication within the neurofibromatosis type 1 gene (NF1) and reciprocal $\mathrm{t}(15 ; 16)(\mathrm{q} 26.3 ; \mathrm{q} 12.1)$ translocation in familial association of NF1 with intestinal neuronal dysplasia type B (IND B)

EDITOR-Neurofibromatosis type 1 (NF1) is a common human disorder (1/3500 live births) with neuroectodermal involvement resulting in dermatological manifestations of café au lait spots, cutaneous/subcutaneous neurofibromas, and freckling of major folds. ${ }^{1}$ Hamartomas of the irides (Lisch nodules), well observed on slit lamp examination, are helpful phenotypic markers. Owing to diagnostic uncertainties, especially in young patients, an international scoring system has been discussed and agreed upon. ${ }^{2}$ Half of the cases result from fresh mutations, others show an autosomal dominant mode of inheritance. The gene mutated in NF1 maps to $17 \mathrm{q} 11.2$, is composed of 57 plus at least three alternatively spliced exons, ${ }^{3}$ and is of ubiquitous expression. The encoded product, referred to as neurofibromin, is a member of the so called GTPase activating proteins (GAPs), and is an upstream downregulator of the p21Ras/ Raf/MAPkinase signalling pathway. ${ }^{4}$ Though genetic homogeneity is a hallmark of this condition, phenotypic heterogeneity has been exemplified by an extreme spectrum of diversity ranging from malformation or malignant variants to virtually benign dermatological changes. ${ }^{1}$

In particular, and among the many causes for gastrointestinal involvement in NF1 patients, the association with intrinsic intestinal dysmotility (IID), resulting from intestinal neuronal dysplasia type $\mathrm{B}$ (IND B) ${ }^{56}$ or aganglionic

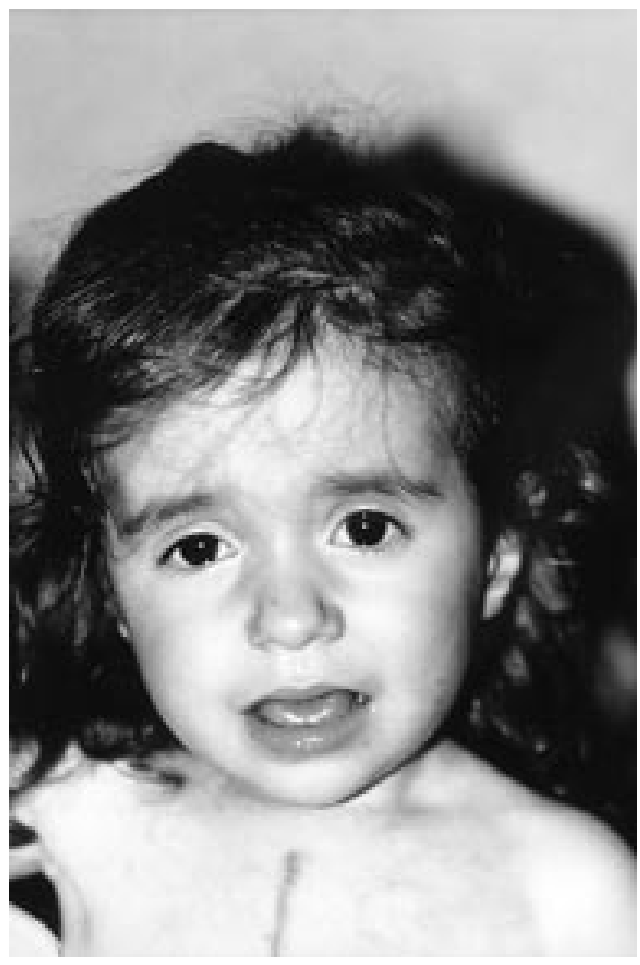

Figure 1 The proband aged 27 months. Note downward slanting palpebral fissures, apparent hypertelorism, depressed nasal root, small, tapered chin, and scar from sternotomy. megacolon (Hirschsprung's disease, HSCR) ${ }^{7}$ has been documented and is now well established.

We report here a family showing aggregation of NF1 and IID in two sibs, in one of whom congenital megacolon necessitated a Duhamel abdominoperineal pull through with tired suction biopsies of the colon and analysis of the whole excised specimen indicating IND B. This kindred provided a unique opportunity to unravel the genetic bases for the association between two such disorders of neural crest cell development.

The proband was seen at the age of 27 months for investigation of a multiple congenital anomaly/mental retardation (MCA/MR) complex. This young female was born to unrelated white parents. A familial component of both neurofibromatosis type 1 and severe intestinal dysmotility was shown. According to the history, intrauterine growth retardation had been evident from 6 months of gestation. Recurrent caesarean section was performed at 38 weeks of gestation. Birth weight was $2360 \mathrm{~g}$, crown-heel length $46 \mathrm{~cm}$, and OFC $32 \mathrm{~cm}$. The Apgar scores were 8 and 10 at one and five minutes. Congenital heart disease was then diagnosed owing to heart failure with evidence of ventricular septal defect (membranous), persistent ductus arteriosus, and coarctation of the aorta. A two step surgical procedure including tissue grafting led to complete recovery. However, unresolved growth retardation ranging between -3 and $-4 \mathrm{SD}$, cognitive impairment, the presence of multiple cutaneous café au lait spots, and persistent severe constipation indicated a possible MCA/MR syndrome.

On examination, the child was of short stature $(76 \mathrm{~cm}$, $-3.5 \mathrm{SD})$, low weight $(8.22 \mathrm{~kg},-3.25 \mathrm{SD})$, and had relative macrocephaly $(48 \mathrm{~cm}, \sim$ mean $)$. A distended abdomen contrasted with a generally wasted appearance $(\mathrm{BC} / \mathrm{OFC}=0.26$, normal $\geqslant 0.30)$. Minor facial anomalies were also noted including frontal bossing, temporal narrowing, depressed nasal root, small, tapered chin, and hypoplastic ear lobes. There were downward slanting palpebral fissures but no true hypertelorism $(\mathrm{ICD}=25 \mathrm{~cm}$, $\mathrm{OCD}=67 \mathrm{~cm}$ ) (fig 1). High vaulted (uncleft) palate as well as hypoplastic and widely spaced teeth were also observed. There was apparent anterior displacement of the anus. The extremities were normal. Dermatological scrutiny showed $>10$ large $(>5 \mathrm{~mm})$ café au lait spots over her trunk and several achromic patches on the four limbs. There were no cutaneous/subcutaneous neurofibromas and axillary freckling was not a feature. The child could not walk unaided but rather crawled on all fours, and speech consisted of

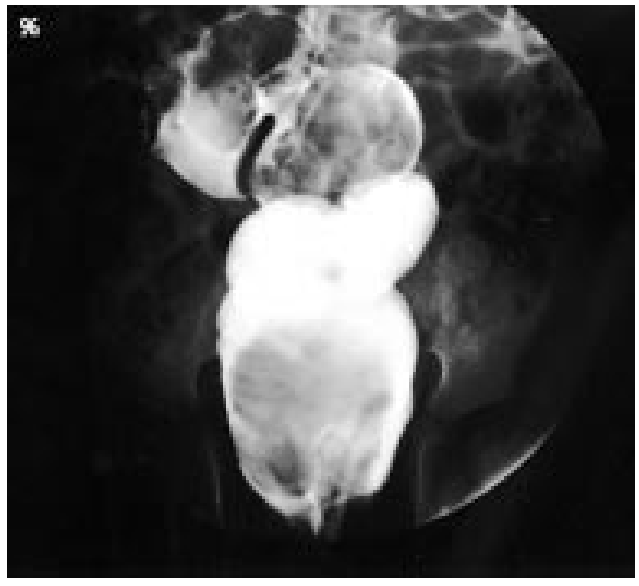

Figure 2 Contrast enema. Distended intestines are consistent with the diagnosis of congenital megacolon. 

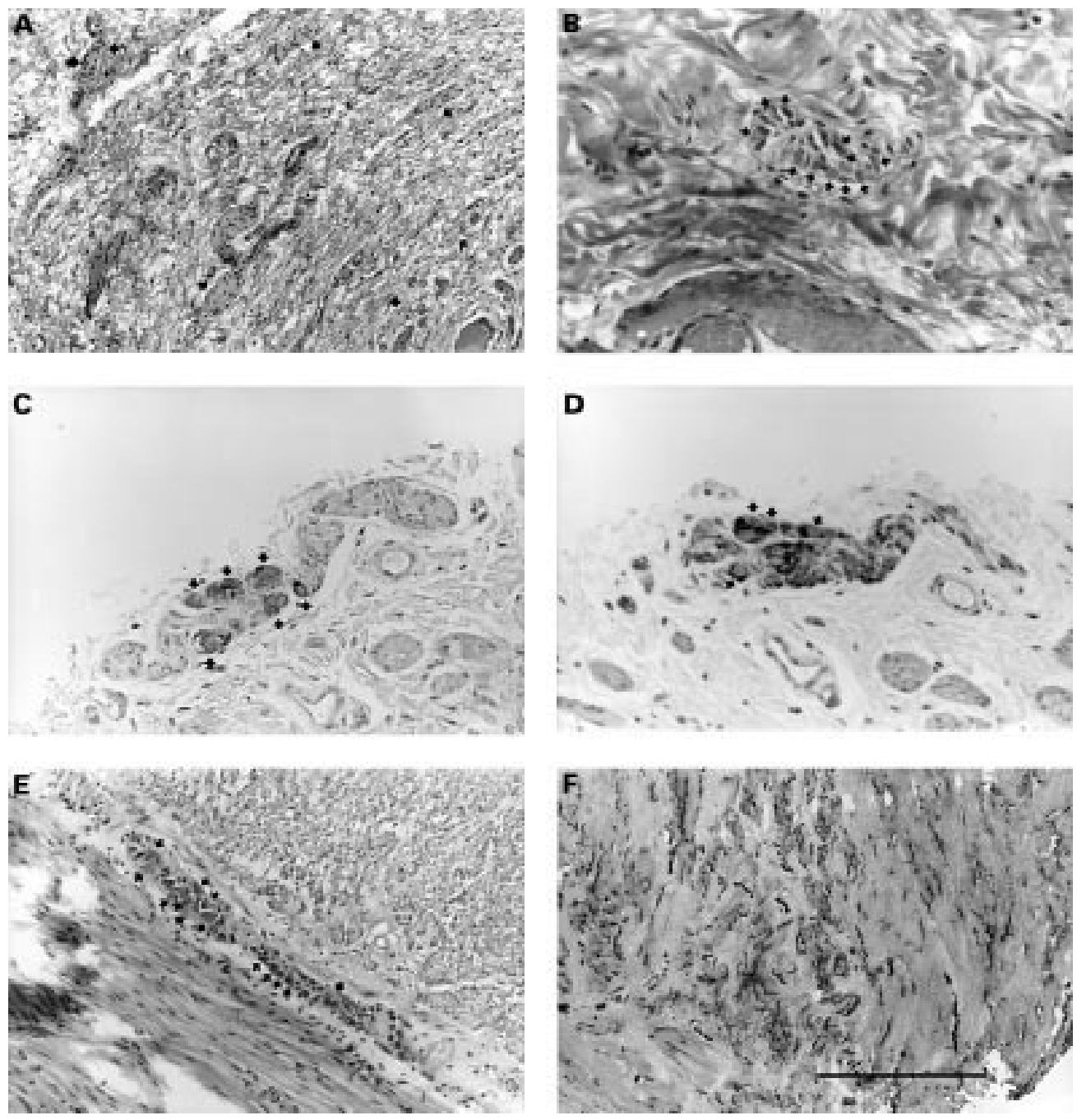

Figure 3 Intestinal neuronal dysplasia. Suction biopsies of the rectum, sigmoid, and left colon, and the subsequent colectomy specimen were routinely processed for histology and immunostained for neurone specific enolase (NSE), a marker of neurones, and protein S100, a marker of Schwann cells, in order to identify intrinsic nervous structures better. In addition, acetylcholinesterase activity could be ascertained from an archival frozen sample.

(A) Abnormally increased density of the nervous structures (arrows) and Schwann cell hyperplasia are consistent with hyperplasia of the rectal submucosal plexuses; ganglion cells (double arrow) are occasionally visible at this magnification (haematoxylin, eosin, and saffron, scale=400 $\mu \mathrm{m}$ ). (B) "Giant" submucosal sigmoid ganglion, that is, containing more than 10 neurones (arrows) with typical, large, amphophilic cytoplasm (haematoxylin, eosin, and saffron, scale $=150 \mu \mathrm{m})$. Neurones of a myenteric plexus are visible after immunostaining with anti-NSE antibody (C, arrows) and are negative for antiprotein S100 antibody, which specifically stains the Schwann cells (D, arrows) (serial sections, immunoperoxidase, scale=150 $\mu \mathrm{m})$. (E) A myenteric sigmoid plexus showing numerous neurones (arrows, haematoxylin, eosin, and saffron, scale $=400 \mu \mathrm{m})$. (F) Acetylcholinesterase staining of the rectal muscular layer showing numerous, coarse, and undulating fibres (dark) (frozen section, scale $=750 \mu \mathrm{m}$ ).

only a few words. The developmental quotient score was 57, as ascertained by the Binet test.

Cholesterol was slightly raised $(6 \mathrm{mmol} / \mathrm{l}$, normal $<5.3)$, but triglycerides were within normal limits. Metabolic screening was negative. Skeletal $x$ ray showed evidence of delayed bone age (18 months), and soft tissue abdominal $x$ ray showed faecal impaction with stercoliths. Distended intestines on contrast enema indicated megacolon (fig 2). Ophthalmological evaluation, including slit lamp examination of the irides and fundoscopy, was normal. MRI showed enlargement of the right rear aspect of the myelencephalon and a bright signal with contrast enhancement consistent with the diagnosis of hamartoma or low grade glioma. Bright signals were also evident at the medial cerebellar peduncle and in the left semioval centre on T2 weighted sequences, consistent with so called unidentified bright objects (UBOs).

Because of the congenital megacolon, surgical biopsies of the colon and rectum were performed and were found to be consistent with aganglionosis with Schwann cell hyperplasia in the Auerbach plexuses and hypoganglionosis with Schwann cell hyperplasia in the Meissner plexuses. A Duhamel abdominoperineal pull through was thus per- formed. Analysis of suction biopsies of the rectum, sigmoid, and left colon and of the whole subsequent colectomy specimen pointed to intestinal neuronal dysplasia type B (IND B), based on the presence of abnormal submucosal plexuses showing focal hyperplasia (in terms of density and sizes), occasional giant ganglia harbouring $>10$ neurones, and nerve cell buds along afferent nerves. The presence of giant ganglia, two to three times as large as their normal counterparts, was set forth as the only reliable, age independent diagnostic criterion for IND B, ${ }^{8}$ since hyperplasia of the submucosal plexuses, an increase in acetylcholinesterase (AChE) activity in the nerve fibres of the lamina propria, and low SDH activity in nerve cells were shown to normalise with the ongoing maturation of the enteric nervous system. In addition, myenteric plexuses were either normal or hypertrophied, with numerous mature neurones (fig 3).

In order to address the possibility of a cytogenetic aberration in relation to a MCA/MR syndrome in the proband, her chromosome complement was established. From analysis of high resolution RBG banded chromosomes, it was apparent that she had a cytogenetically bal- 


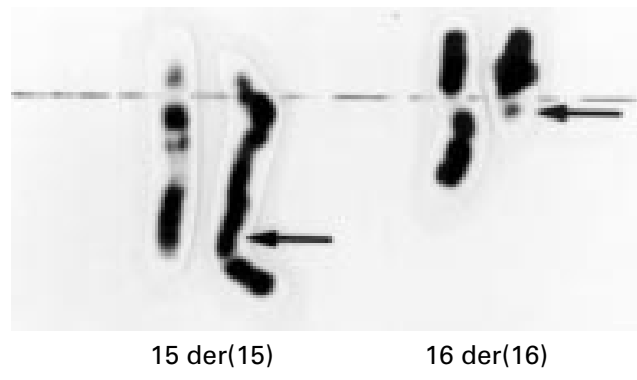

Figure 4 Reciprocal balanced translocation. Wild type as well as derivative chromosomes 15 and 16 from the proband are shown prepared from whole blood lymphocytes with RBG labelling at the 550 band level, following the guidelines of the International System for Human

Cytogenetic Nomenclature (ISCN 1995). Arrows point to breakpoints on $\operatorname{der}(15)$, in 15q26.3, and on $\operatorname{der}(16)$, in 16q12.1.

anced reciprocal translocation, her specific chromosomal constitution being 46,XX, t(15;16)(q26.3;q12.1) (fig 4). This abnormality was inherited from her father (I.1, fig 5A), whose lymphocytes harboured the same translocated chromosomes and was also shared by her older sister (II.1) and healthy brother (II.2) (data not shown; see below for additional family data).

The mother of the proband (I.2, fig 5A) presented with classical neurofibromatosis type 1 with multiple large café au lait spots and cutaneous/subcutaneous neurofibromas. Her condition was seemingly inherited through the maternal grandmaternal lineage. The father of the proband (I.1) had no apparent dermatological ailment, malformation, or cognitive alteration. The older daughter (II.1) presented with café au lait spots and had some degree of problem with school performance and cognitive impairment (VIQ=76, PIQ=83, TIQ=77, according to WISC-R). She had severe constipation with megacolon and a clinical course typical of HSCR until a favourable outcome followed successful medical treatment. The sibship also included an older brother (II.2) who had not, to our knowledge, been referred for dermatological, morphologi- cal, or cognitive problems. A spontaneous abortion, occurring at 2 months of gestation (II.3), was also reported, without further details.

This familial association of NF1 and IND B provided a unique opportunity to test for alternative causal mechanisms, namely the random aggregation of two common monogenic disorders versus a discrete neurocristopathy with possible genotype-phenotype correlation at the NF1 locus or modifying loci lying elsewhere in the genome.

Indeed, although no specific gene for IND B has been found, the latter condition may segregate with typical monogenic HSCR. ${ }^{9}$ Consistently, and following strict diagnostic guidelines, $\sim 30 \%$ of IND B patients have accompanying aganglionosis, that is, HSCR. ${ }^{10}$ Therefore, screening for a mutation in the genes found to be mutated in monogenic non-syndromic HSCR, that is, the RET proto-oncogene, ${ }^{11-13}$ the genes encoding endothelin receptor $\mathrm{B}(E D N R B),{ }^{9}{ }^{14}{ }^{15}$ or its ligand endothelin 3 (EDN3), ${ }^{16}$ was a prerequisite to dissecting this familial association further. Molecular analysis of the RET proto-oncogene was carried out using DGGE based on psoralen modified primers for exons 3, 5, 9-13,16, 18, 20, and SSCP for exons $1,2,4,6-8,14,15,17$ and 19 , as previously described. ${ }^{13}$ SSCP in conditions previously determined was similarly carried out for the seven $E D N R B^{9}$ and the five EDN3 exons. ${ }^{16}$ Following these procedures, no mobility shift was observed. We assume that no mutation of the relevant genes was present in the proband's DNA.

Since none of these genes was faulty in the proband, which favoured a discrete neurocristopathy, it was of particular interest to identify the NF1 lesion. The latter was detected as a result of routine screening for the previously reported recurrent $\mathrm{R} 816 \mathrm{X}$ mutation using previously described PCR amplification of NF1 exon 16 followed by restriction with endonuclease $H p h I .{ }^{17}$ Sequence analysis, carried out in conditions previously specified, ${ }^{17}$ showed a heterozygous tandem duplication of the $7 \mathrm{bp}$ motif (5' CCTTCAC 3'), nt 2418-2424, inclusive, lying towards

A

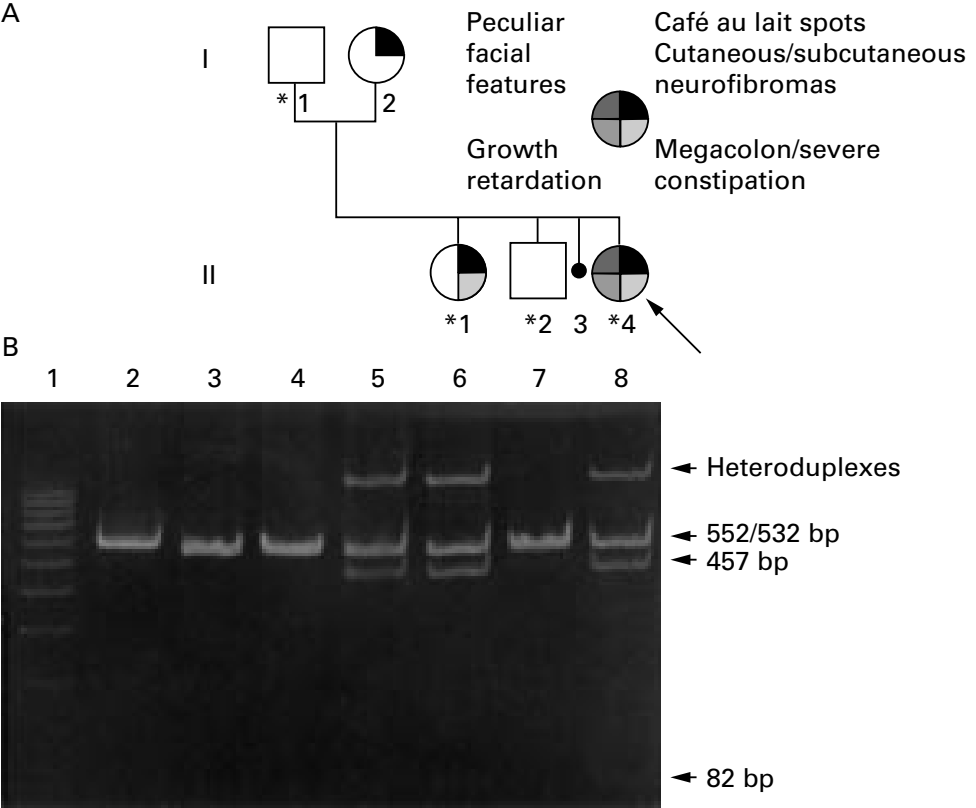

Figure 5 (A) Family pedigree. Arrow indicates the proband. II. 3 was a miscarriage. Complex phenotypic traits are specified as shown in the key. The presence of the reciprocal $t(15 ; 16)(q 26.3 ; q 12.1)$ translocation in I.1, II.1, II.2, and II.4 is indicated by an asterisk. The proband and her older sister (II.1) both have NF1 skin symptoms, have severe constipation/megacolon, and harbour the familial cytogenetically balanced reciprocal translocation. (B) Restriction with HphI. The NF1 exon 16 amplimer is shown restricted for I.1 (lane 4), I.2 (lane 5), II.1 (lane 6), II.2 (lane 7), and II.4 (lane 8), co-electrophoresed with molecular weight marker GenLadder ${ }^{\mathrm{TM}} 100$ (Genaxis Biotechnology, Montigny-le-Bretonneux, France; lane 1). Arrowheads indicate theoretical fragment sizes in base pairs ( $b p)$ as compared to a healthy control, unrestricted (552 bp fragment, lane 2) and restricted (532 bp fragment, lane 3). Healthy subjects I. 1 and II.2 display the expected wild type 532 bp fragment, whereas I.2, II.1 and II.4, diagnosed with NF1, have wild type $532 \mathrm{bp}$ as well as mutant $457 \mathrm{bp}$ and $82 \mathrm{bp}$ fragments. Note the presence of heteroduplexes in lanes 5, 6, and 8. 


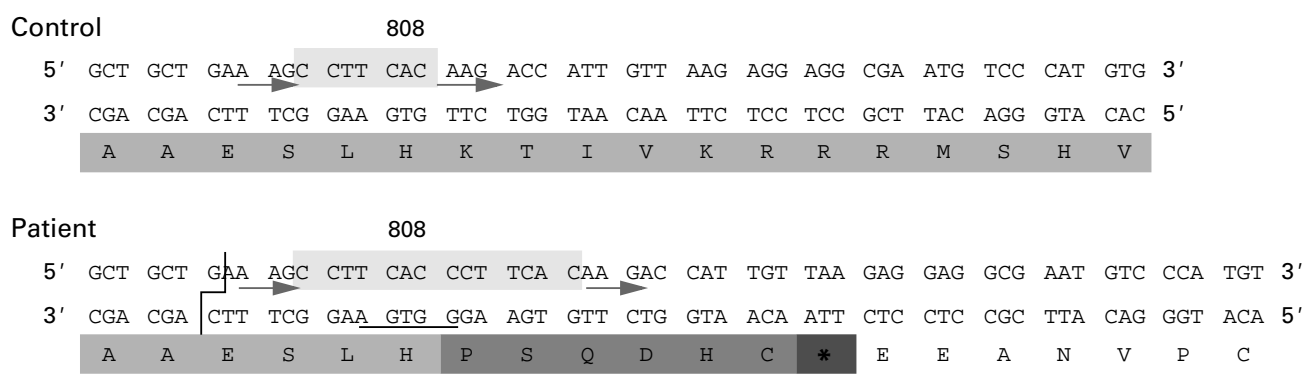

Target motif $\quad \rightarrow$ Direct repeat
Wild type amino acid sequence $\longrightarrow$ Hphl cleavage site
$\begin{aligned} & \text { New amino acids } \\ & \text { Premature stop codon }\end{aligned}-$ Hphl recognition site

Figure 6 NF1 tandem duplication. Double stranded sequence of NF1 exon 16, 5' extremity, is represented in control and patient with translation into protein. The tandem duplication of a $7 \mathrm{bp}$ target motif flanked by two short direct repeats in the patient results in a frameshift mutation and leads to a putative truncated protein as shown by the insertion of six new amino acids, immediately followed by a premature translation termination codon (TAA). This tandem duplication also generates a recognition site for type II endonuclease HphI, as indicated above.

the $5^{\prime}$ extremity of the exon and flanked by two short direct tandem repeats (5' AAG $\left.3^{\prime}\right)$. This DNA lesion (24242425 insCCTTCAC) caused a frameshift 3 ' to codon 808 , unchanged, with the addition of six new codons immediately followed by a translation termination signal (TAA), and generated a bona fide recognition site for $H p h \mathrm{I}$ (5' GGTGA 3') (fig 6). This specific lesion featured as a rare mutational event (one case identified among $>200$ independent NF1 chromosomes tested; data not shown) and was therefore not amenable to genotype-phenotype correlation analysis. However, this out of frame duplication, lying 5 ' to the GAP related domain (GRD) specifying region of the gene, was most probably a null mutation and therefore probably did not cause variation in the phenotype.

Using the aforementioned screening method, the status of the rest of the family with regard to the mutation was eventually determined. Predictably, the mother and sister, diagnosed with NF1, were heterozygotes for the 24242425 insCCTTCAC lesion, whereas the father and older brother were both wild type homozygotes (fig 5B).

Alleles that modify the severity of the phenotype (or penetrance) of a given, well established monogenic factor, that is, mutation of RET, EDN3, or EDNRB in HSCR, with or without coexisting IND B, have been postulated and some of the relevant genes or loci subsequently identified. The first such example was illustrated by a large inbred Mennonite HSCR pedigree that segregated a missense mutation in $E D N R B^{18}$ and otherwise showed linkage disequilibrium with marker alleles mapped to 21q22. This finding was highly suggestive of a HSCR genetic modifier linked to this chromosomal region, ${ }^{19}$ which might elsewhere account for high HSCR prevalence among trisomy 21 patients. ${ }^{20}$ More compelling evidence for a HSCR modifier is exemplified by the genes encoding glial cell line derived neurotrophic factor $(G D N F)^{21-23}$ and, more recently, neurturin (NRTN), ${ }^{24}$ two highly homologous natural ligands of the RET tyrosine kinase receptor protein. Indeed, since GDNF and NRTN were found to be mutated in families also segregating well characterised $R E T$ alleles, it was postulated that alterations of these genes were not sufficient in themselves to cause HSCR, but that they probably contributed to the severity of the phenotype, or to higher penetrance of the RET mutations.

As to NF1, analysis of several quantitative or binary traits among a large sample of familial cases concluded that the number of café au lait spots and the number of cutaneous neurofibromas, showing high concordance among $\mathrm{MZ}$ twin pairs but weaker concordance in more distant relatives, were determined by non-allelic, "modifying" loci. ${ }^{25}$ Absence of correlation between the characters analysed suggested that these loci were also trait specific. The presence or absence of intestinal neuronal dysplasia, or bona fide HSCR, is a rare configuration that could not have been assessed. However, modifying loci remain a strong possibility, especially since NF1 and HSCR/IND B are both characterised by disruption or maldevelopment of neural crest cell derivatives. In other words, alleles of genes whose products interfere with the determination, migration, or differentiation of ganglion cells of the enteric plexuses might, in the presence of a perturbed Ras signalling pathway, lead to IID. In this respect, it is noteworthy that the proband's NF1 phenotype is consistent with the involvement of a broad spectrum of neural crest cell derivatives, that is, also including motor neurones of the enteric nervous system, conotruncus, and cranial crest mesectoderm. ${ }^{26}$

Finally, the most salient aspect of this report is the cosegregation, in two sisters affected with NF1 and megacolon, of an NF1 lesion inherited from the mother, in whom it results in a classical presentation of the condition, and of a cytogenetically balanced reciprocal translocation inherited from the father and shared by an older brother, in whom this chromosomal aberration has no apparent pathogenicity. None of the translocation breakpoints (15q26.3 and 16q12.1) has yet been involved in HSCR or IND $\mathrm{B}$, alone or in a more complex phenotype (see the review by Passarge ${ }^{27}$ and a recently recognised entity by Mowat et $a l^{28}$ ). Therefore, these chromosomal regions provide obvious candidate locations for additional NF1 or HSCR/IND B modifiers or both.

The authors are grateful to the patients for their participation, to Dr J-F Chateil for helpful diagnostic information, and to Dr D Récan and co-workers for the establishment and maintenance of lymphoblastoid cell lines. This work was supported by the French Ministère de l'Education Nationale, de la Recherche et de l'Enseignement Supérieur, and the Association pour la Recherche sur le Cancer. MB is the recipient of a scholarship allocated by the Fondation pour la Recherche Médicale.

MICHEL BAHUAU* INGRID LAURENDEAU* ANNA PELET $†$ BRIGITTE ASSOULINE* THIERRY LAMIREAU LAURENCE TAINES BRIGITTE LE BAIL PIERRE VERGNES * SERGE GALLET †† MICHEL VIDAUD * 
STANISLAS LYONNET + DIDIER LACOMBE DOMINIQUE VIDAUD*

${ }^{\star}$ Laboratoire de Génétique Moléculaire, Faculté de Pharmacie, Université Paris V, 4 Avenue de l'Observatoire, 75006 Paris, France tUnité de Recherches sur les Handicaps Génétiques de l'Enfant, INSERM U393, Hôpital Necker Enfants-Malades, Paris, France ¥Service de Pédiatrie et Génétique Médicale, Groupe Hospitalier Pellegrin, Centre Hospitalier Universitaire de Bordeaux, Bordeaux, France SLaboratoire de Génétique, Groupe Hospitalier Pellegrin, Centre Hospitalier Universitaire de Bordeaux, Bordeaux, France -Laboratoire d'Anatomie et Cytologie Pathologiques, Groupe Hospitalier Pellegrin, Centre Hospitalier Universitaire de Bordeaux, Bordeaux, France **Service de Chirurgie Pédiatrique, Groupe Hospitalier Pellegrin, Centre Hospitalier Universitaire de Bordeaux, Bordeaux, France †Département de Pédiatrie, Centre Hospitalier Général de Montluçon, Montluçon, France

Correspondence to: Dr D Vidaud (mvidaud@teaser.fr) or Dr Lacombe (didier.lacombe@chu-aquitaine.fr)

1 Riccardi VM. Neurofibromatosis - phenotype, natural history, and pathogenesis. 2nd ed. Baltimore: The Johns Hopkins University Press, 1992.

2 Stumpf DA, Alksne JF, Annegers JF, et al. Neurofibromatosis - conference statement. Arch Neurol 1988;45:575-8.

$3 \mathrm{Li} \mathrm{Y,} \mathrm{O'Connell} \mathrm{P,} \mathrm{Huntsman} \mathrm{Breidenbach} \mathrm{H}$, et al. Genomic organization of the neurofibromatosis 1 gene (NF1). Genomics 1995;25:9-18.

4 Martin GA, Viskochil D, Bollag G, et al. The GAP-related domain of the neurofibromatosis type 1 gene product interacts with ras p21. Cell 1990;63: 843-9.

5 Saul RA, Sturner RA, Burger PC. Hyperplasia of the myenteric plexus. Its association with early infantile megacolon and neurofibromatosis. Am f Dis Child 1982;136:852-4.

6 Feinstat T, Tesluk H, Schuffler MD, et al. Megacolon and neurofibromatosis: a neuronal intestinal dysplasia. Case report and review of the literature. Gastroenterology 1984;86:1573-9.

7 Clausen N, Andersson P, Tommerup N. Familial occurrence of neuroblastoma, von Recklinghausen's neurofibromatosis, Hirschsprung's aganglionomis and jaw-winking syndrome. Acta Paediatr Scand 1989;78:736-41

8 Meier-Ruge W, Gambazzi F, Käufeler RE, Schmid P, Schmidt CP. The Meier-Ruge W, Gambazzi F, Käufeler RE, Schmid P, Schmidt CP. The
neuropathological diagnosis of neuronal intestinal dysplasia (NID B). Eur f Pediatr Surg 1994;4:267-73.

9 Amiel J, Attié T, Jan D, et al. Heterozygous endothelin receptor B $(E D N R B)$ mutations in isolated Hirschsprung disease. Hum Mol Genet 1996;5:355-7.

10 Meier-Ruge WA, Brönnimann PB, Gambazzi F, Schmid PC, Schmidt CP, Stoss F. Histopathological criteria for intestinal neuronal dysplasia of the submucosal plexus (type B). Virchows Arch 1995;426:549-56.
11 Edery P, Lyonnet S, Mulligan LM, et al. Mutations of the RET protooncogene in Hirschsprung's disease. Nature 1994;367:378-80.

12 Romeo G, Ronchetto P, Luo Y, et al. Point mutations affecting the tyrosine kinase domain of the RET proto-oncogene in Hirschsprung's disease. Nature 1994;367:377-8.

13 Attié T, Pelet A, Edery P, et al. Diversity of RET proto-oncogene mutations in familial and sporadic Hirschsprung disease. Hum Mol Genet 1995;4: 1381-6.

14 Auricchio A, Casari G, Staiano A, Ballabio A. Endothelin-B receptor mutations in patients with isolated Hirschsprung disease from a non-inbred population. Hum Mol Genet 1996;5:351-4.

15 Kusafuka T, Wang Y, Puri P. Novel mutations of the endothelin-B receptor gene in isolated patients with Hirschsprung's disease. Hum Mol Genet 1996;5:347-9.

16 Bidaud C, Salomon R, Van Camp G, et al. Endothelin-3 gene mutations in isolated and syndromic Hirschsprung disease. Eur $\mathcal{f}$ Hum Genet 1997;5:247-51.

17 Bahuau M, Houdayer C, Assouline B, et al. Novel recurrent nonsense mutation causing neurofibromatosis type 1 (NF1) in a family segregating both NF1 and Noonan syndrome. Am $\mathcal{F}$ Med Genet 1998;75:265-72.

18 Puffenberger EG, Hosoda K, Washington SS, et al. A missense mutation of the endothelin-B receptor gene in multigenic Hirschsprung's disease. Cell 1994;79:1257-66.

19 Puffenberger EG, Kauffman ER, Bolk S, et al. Identity-by-descent and association mapping of a recessive gene for Hirschsprung disease on human chromosome 13q22. Hum Mol Genet 1994;3:1217-25.

20 Garver KL, Law JC, Garver B. Hirschsprung disease: a genetic study. Clin Genet 1985;28:503-8.

21 Angrist M, Bolk S, Halushka M, Lapchak PA, Chakravarti A. Germline mutations in glial cell line-derived neurotrophic factor $(G D N F)$ and $R E T$ in a Hirschsprung disease patient. Nat Genet 1996;14:341-4

22 Salomon R, Attié T, Pelet A, et al. Germline mutations of the RET ligand GDNF are not sufficient to cause Hirschsprung disease. Nat Genet 1996;14:345-7.

23 Hofstra RMW, Osinga J, Buys CHCM. Mutations in Hirschsprung disease: when does a mutation contribute to the phenotype. Eur f Hum Genet 1997; 5:180-5.

24 Doray B, Salomon R, Amiel J, et al. Mutation of the RET ligand, neurturin, supports multigenic inheritance in Hirschsprung disease. Hum Mol Genet 1998;7:1449-52

25 Easton DF, Ponder MA, Huson SM, Ponder BAJ. An analysis of variation in expression of neurofibromatosis (NF) type 1 (NF1): evidence for modifying genes. Am f Hum Genet 1993;53:305-13.

26 Bolande RP. Neurocristopathy: its growth and development in 20 years. Pediatr Pathol Lab Med 1997;17:1-25.

27 Passarge E. Whither polygenic inheritance: mapping Hirschsprung disease. Nat Genet 1993;4:325-6.

28 Mowat DR, Croaker GDH, Cass DT, et al. Hirschsprung disease, microcephaly, mental retardation, and characteristic facial features: delineation of a new syndrome and identification of a locus at chromosome $2 \mathrm{q} 22$-q23. $f$ Med Genet 1998;35:617-23.

\section{Identification of novel alleles at a polymorphic microsatellite repeat region in the human NRAMP1 gene promoter: analysis of allele frequencies in primary biliary cirrhosis}

EdITOR-Primary biliary cirrhosis (PBC) is a chronic, slowly progressive cholestatic liver disease believed to result from autoimmune mechanisms. The initiation of the disease is likely to be multifactorial with genetic, infectious, and environmental factors contributing. A familial predisposition to PBC has been reported, but studies to investigate an association between PBC and polymorphisms at a number of genetic loci have not been conclusive. The aetiology of the disease remains unknown but it has been suggested that $\mathrm{R}$ forms of $E$ coli $^{1}$ and Mycobacterium gordona ${ }^{23}$ may play a potentially pathogenic role in PBC, though this has not been established. A common characteristic feature of PBC is the presence of granulomas and it is interesting to note that these tend to disappear as the lesions progress and fibrosis and cholestasis appear, that is, secondary effects of tissue damage.

NRAMP1 (natural resistance associated macrophage protein 1) was isolated as the human homologue of the mouse nramp1 gene (previously designated Ity/Lsh/Bcg) which, when mutated, is responsible for susceptibility to a number of macrophage trophic intracellular pathogens including Mycobacterium bovis, Salmonella typhimurium, and Leishmania donovani. ${ }^{4}$ Expression of the gene is restricted to cells of the mononuclear phagocytic system (macrophages and granulocytes) ${ }^{5}$ and it plays an important role in the activation of macrophages and innate immunity. When nramp1 is mutated, mice fail to control pathogen growth in the early stages of infection. Sequence analysis of nramp1 and recent functional studies suggest that the gene encodes a multispanning transmembrane transporter protein ${ }^{6}$ with specificity for divalent metal cations, ${ }^{7}$ but its physiological role in relation to macrophage function is still poorly understood. In the human gene at least 10 polymorphic sites have been described, ${ }^{8-10}$ one of which spans a microsatellite repeat region in the 5 ' untranscribed promoter region of the gene. This is a functional polymorphism affecting levels of NRAMP1 expression. ${ }^{11}$ The alleles at this site have been inconsistently reported; Blackwell et $a l^{9}$ initially reported identification of four alleles where alleles 1, 2, 3, and 4 had 11, 10, nine, and four repeats of the final dinucleotide repeat in the sequence $\mathrm{t}(\mathrm{gt})_{5} \mathrm{ac}(\mathrm{gt})_{5} \mathrm{ac}(\mathrm{gt})_{\mathrm{n}} \mathrm{g}$. In subsequent reports they have designated the sequence $\mathrm{t}(\mathrm{gt})_{5} \mathrm{ac}(\mathrm{gt})_{10} \mathrm{~g}$ as allele $4^{11-13}$ and have most recently reported allele 4 to have the sequence $\mathrm{t}(\mathrm{gt})_{5} \mathrm{ac}(\mathrm{gt})_{9} \mathrm{~g}^{14}$. Liu et $a l^{8}$ identified three alleles at this site which they allocated alleles 1, 2, and 3 with 2 bp 
Mnll

ggacatgaagactcgcattag|gccaacgaggggtcttggaactccagatcaaagag cctgtacttctgagcgtaat|ccggttgct ccccagaaccttgaggtctagtttctc

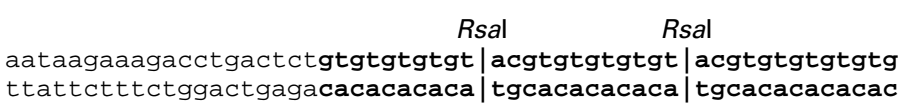

\section{Mnll}

tgtgt | gtggcagaggggggtgtggtcatggggtattgacatgaatacgcaaggggc acac|acaccgtct ceccccacaccagtaccccataactgtact tatgcgttcccco

aggaagcatctgaatcagagctaa
tccttcgtagactttagtctcgatt

Figure 1 Sequence of the promoter region of the human NRAMP1 (Accession number X82016, 59-240 bp) amplified by PCR to genotype the polymorphic microsatellite region shown in bold. The RsaI and MnlI restriction enzyme sites used to digest the amplified DNA are shown. The enzymes recognise the following sites and cut at the position shown by the vertical slash. $n$ represents any base. MnlI $(n)$ gagg I $(n)$,ctcc RsaIgtlac. The sequence for allele 3 is used in this figure. Sequences of the other alleles identified in this study and those previously published are shown in table 1.

increments of increasing size and allele 1 having the sequence $\mathrm{t}(\mathrm{gt})_{7} \mathrm{ac}(\mathrm{gt})_{5} \mathrm{ac}(\mathrm{gt})_{9} \mathrm{~g} .{ }^{8}$ We adopted and added to the allele naming system used by Blackwell et $a l^{911-14}$ as we have shown evidence from restriction enzyme digestion and sequencing that three of the alleles we have identified are consistent with their reported alleles 1,2 , and 3 .

Associations with NRAMP1 and susceptibility to a number of diseases including Crohn's disease ${ }^{15}$ tuberculosis, ${ }^{16}$ leprosy, ${ }^{17}$ and rheumatoid arthritis (RA) ${ }^{12} 13$ have been reported. The reported NRAMP1 and RA association is with the allele driving highest levels of NRAMP1 expression (allele 3 ) of the microsatellite repeat region polymorphism discussed above. Allele 3 was found to be transmitted to RA affected children in preference to allele 2 in a study using identity by descent sib pair analysis. ${ }^{12} 13$ We investigated this polymorphic site in patients with PBC.

Using restriction fragment length polymorphism (RFLP) analysis we genotyped 46 PBC patients, 76 alcoholic liver disease (ALD) patients, 39 hepatitis C patients, and 78 normal, healthy, non-cirrhotic subjects for the microsatellite repeat polymorphism in the promoter region of the NRAMP1 gene. PCR products of approximately $194 \mathrm{bp}$, generated using NRAMPFpol GGACATGAAGACTCGCATTAGG (59-70 bp Genbank Accession number X82016) and NRAMPRpol TTAGCTCTGATTTCAGATGCTTCC (240-217 bp Genbank Accession number X82016) PCR primers, were digested separately with $R s a \mathrm{I}$ and $M n l \mathrm{I}$, resolved on $6 \%$ denaturing polyacrylamide gel by electrophoresis, and silver stained. ${ }^{18}$ We found three alleles as previously reported, ${ }^{911-14}$ but in addition two new alleles which we named allele 5 and allele 6.

The PCR products from cases with these novel genotypes were cloned into the vector pCR2.1 using Invitrogen TA Cloning System Version 2.0 and the plasmids used to transform competent XL-2 blue cells. The cloned DNA inserts from successful transformants showing the appropriate RFLP pattern were then sequenced. Allele 5 was found to have the sequence $\mathrm{t}(\mathrm{gt})_{4} \mathrm{ac}(\mathrm{gt})_{5} \mathrm{ac}(\mathrm{gt})_{10} \mathrm{~g}$ with

Table 1 Summary of alleles of human NRAMP1 5' promoter polymorphic site. Sequence of the alleles identified in previous studies (alleles 1-4) and in this study (alleles 1, 2, 3, 5, and 6)

\begin{tabular}{|c|c|}
\hline Allele $1^{911-14}$ & $\mathrm{t}(\mathrm{gt})_{5} \mathrm{ac}(\mathrm{gt})_{5} \mathrm{ac}(\mathrm{gt})_{11} \mathrm{ggcaga}(\mathrm{g})_{6}$ \\
\hline $\begin{array}{l}\text { Allele } 2^{911-14} \\
\text { Allele } 3^{911-14} \\
\text { Allele } 4^{11-13} \\
\text { Allele } 4^{9} \\
\text { Allele } 4^{14} \\
\text { Allele } 5 \\
\text { Allele } 6\end{array}$ & $\begin{array}{l}\mathrm{t}(\mathrm{gt})_{5} \mathrm{ac}(\mathrm{gt})_{5} \mathrm{ac}(\mathrm{gt})_{10} \mathrm{ggcaga}(\mathrm{g})_{6} \\
\mathrm{t}(\mathrm{gt})_{5} \mathrm{ac}(\mathrm{gt})_{5} \mathrm{ac}(\mathrm{gt})_{9} \mathrm{ggcaga}(\mathrm{g})_{6} \\
\mathrm{t}(\mathrm{gt})_{5} \mathrm{ac}(\mathrm{gt})_{10} \mathrm{ggcaga}(\mathrm{g})_{6} \\
\mathrm{t}(\mathrm{gt})_{5} \mathrm{ac}(\mathrm{gt})_{5} \mathrm{ac}(\mathrm{gt})_{4} \mathrm{ggcaga}(\mathrm{g})_{6} \\
\mathrm{t}(\mathrm{gt})_{5} \mathrm{ac}(\mathrm{gt})_{9} \mathrm{ggcaga}(\mathrm{g})_{6} \\
\mathrm{t}(\mathrm{gt})_{4} \mathrm{ac}(\mathrm{gt})_{5} \mathrm{ac}(\mathrm{gt})_{10} \mathrm{ggcaga}(\mathrm{g})_{6} \\
\mathrm{t}(\mathrm{gt})_{5} \mathrm{ac}(\mathrm{gt})_{5} \mathrm{ac}(\mathrm{gt})_{4} \mathrm{at}(\mathrm{gt})_{4} \mathrm{ggcaga}(\mathrm{g})_{7}\end{array}$ \\
\hline
\end{tabular}

a gt deletion in the first $(\mathrm{gt})_{5}$ dinucleotide repeat identified in the other alleles. Allele 6 had the sequence $\mathrm{t}(\mathrm{gt})_{5} \mathrm{ac}(\mathrm{gt})_{5} \mathrm{ac}(\mathrm{gt})_{4} \mathrm{at}(\mathrm{gt})_{4} \mathrm{ggcaga}(\mathrm{g})_{7}$ which had an extra guanidine inserted in a hexanucleotide $g$ repeat $7 \mathrm{bp} 3^{\prime}$ of the final gt of the polymorphic site in addition to the final polymorphic gt repeat being interrupted. Despite finding these novel alleles we have not identified a pattern representing any of the sequences published as allele $4^{911-14}$ in any of the 246 cases analysed.

The sequence of the five alleles we have detected in our study (alleles 1, 2, 3, 5, and 6) and allele 4 reported by Blackwell et $a l^{911-14}$ are shown in table 1. In the PBC population we genotyped, allele 5 was significantly more frequent (Fisher's exact test) in the PBC patients $(8 / 53)$ we studied than in normal controls $(3 / 78)(\mathrm{p}<0.024)$, ALD $(2 / 76)(\mathrm{p}<0.012)$, or hepatitis C patients $(0 / 39)(\mathrm{p}<0.012)$ but was still uncommon.

The repetitive nature of the sequence we analysed requires a stringent, sensitive, and reproducible detection method, owing to the possibility of slippage or infidelity of the Taq polymerase enzyme during PCR amplification. The method we adopted gave consistent results when we analysed DNA extracted from the same blood sample at different times, DNA extracted from blood taken from the same person at different times, and DNA extracted from blood and paraffin embedded material from the same person, and we are confident that our findings are genuine. A number of alleles at this site have previously been reported by sizing this polymorphic region as a single fragment. Our strategy used restriction enzyme digests designed to size both the whole polymorphic site as a single fragment $(M n l \mathrm{I})$ and the size of fragments containing the 5 ' dinucleotide and 3' dinucleotide repeats of the region as distinct entities (RsaI) as shown in fig 1. It was the combined results of these digests which allowed detection of alleles 5 and 6 and confirmation of alleles 1,2, and 3 reported by Blackwell et al. ${ }^{911-14}$ It is important to note that had we been relying solely on results from a single analysis of the size of the microsatellite repeat as a whole, as previous reports have done, allele 5 would have been mistaken for allele 3 , the allele which is at the highest frequency in all previously published reports.

Our finding of two new alleles at this functional polymorphic site warrants further analysis in other populations and investigation into the effect of allele 5 on levels of NRAMP1 expression. Though we may not have identified a biologically significant association with PBC and this site, it is interesting to consider whether previous studies of this polymorphic site may have contained cases with unrecognised allele 5 . 
This work was supported by The Wellcome Trust.

A M GRAHAM

M M DOLLINGER

S E M HOWIE

D J HARRISON

Department of Pathology, Medical School, University of Edinburgh, Teviot Place, Edinburgh EH8 9AG, UK

Correspondence to:

Professor Harrison

1 Hopf U, Stemerowicz R, Rodloff A, et al. Relation between escherichia-coli $\mathrm{R}$ (Rough)-forms in gut, lipid-A in liver, and primary biliary cirrhosis. Lancet 1989;2:1419-22.

2 Vilagut L, Vila J, Vinas O, et al. Cross-reactivity of anti-mycobacterium gordonae antibodies with the major mitochondrial autoantigens in primary biliary cirrhosis. F Hepatol 1994;21:673-7.

3 Vilagut L, Vila J, Pares A, Vinas O, Gines A, Bruguera M. Mycobacterium gordonae DNA in liver tissue of patients with primary biliary cirrhosis. $\mathcal{F}$ Hepatol 1998;21 (suppl):87

4 Vidal SM, Malo D, Vogan K, Skamene E, Gros P. Natural resistance to infection with intracellular parasites: isolation of a candidate for Bcg. Cell 1993;73:469-85

5 Cellier M, Shustik C, Dalton W, et al. Expression of the human NRAMP1 gene in professional primary phagocytes: studies in blood cells and in HL-60 promyelocytic leukemia. $\mathcal{F}$ Leukoc Biol 1997;61:96-105.

6 Cellier M, Prive G, Belouchi A, et al. Nramp defines a family of membraneproteins. Proc Natl Acad Sci USA 1995;92:10089-93.

7 Atkinson PP, Barton CH. Ectopic expression of Nramp1 in COS-1 cells modulates iron accumulation. FEBS Lett 1998;425:239-42.
8 Liu J, Fujiwara TM, Buu NT, et al. Identification of polymorphisms and sequence variants in the human homologue of the mouse natural resistance-associated macrophage protein gene. Am f Hum Genet 1995;56: 845-53

9 Blackwell JM, Barton $\mathrm{CH}$, White JK, et al. Genomic organization and sequence of the human NRAMP gene: identification and mapping of a promoter region polymorphism. Mol Med 1995;1:194-205.

10 Buu NT, Philippe MC, Gros P, Schurr E. Identification of a highly polymorphic length variant in the 3'UTR of NRAMP1. Immunogenetics 1995;42:428-9.

11 Blackwell JM. Structure and function of the natural-resistance-associated macrophage protein (Nramp1), a candidate protein for infectious and autoimmune disease susceptibility. Mol Med Today 1996;2:205-11.

12 Shaw MA, Clayton D, Atkinson SE, et al. Linkage of rheumatoid arthritis to the candidate gene NRAMP1 on 2q35. F Med Genet 1996;33:672-7.

13 Shaw MA, Clayton D, Blackwell JM. Analysis of the candidate gene NRAMP1 in the first 61 ARC national repository families for rheumatoid arthritis. $\mathcal{F}$ Rheumatol 1997;24:212-14.

14 Searle S, Blackwell JM. Evidence for a functional repeat polymorphism in the promoter of the human NRAMP1 gene that correlates with autoimmune versus infectious disease susceptibility. $\mathcal{F}$ Med Genet 1999;36: 295-9.

15 Hofmeister A, Neibergs HL, Pokorny RM, Galandiuk S. The natural resistance-associated macrophage protein gene is associated with Crohn's disease. Surgery 1997;122:173-8.

16 Bellamy R, Ruwende C, Corrah T, McAdam KJ, Whittle HC, Hill AVS. Variations in the NRAMP1 gene and susceptibility to tuberculosis in West Africans. N Engl F Med 1998;338:640-4.

17 Abel L, Sanchez FO, Oberti J, et al. Susceptibility to leprosy is linked to the human NRAMP1 gene. F Infect Dis 1998;177:133-45.

18 Bubb VJ, Curtis LJ, Cunningham C, et al. Microsatellite instability and the role of hMSH2 in sporadic colorectal cancer. Oncogene 1996;12:2641-9.

\section{No evidence for imprinting in distal $18 \mathrm{q}$}

EDITOR-Partial loss of chromosome 18q (MIM 601808) results in characteristic clinical features including mental retardation, short stature, developmental delay, CNS defects, dysmorphic facies, and hearing loss. By phenotype mapping in 26 patients, Strathdee et $a l^{1}$ showed that a region critical for many of the $18 \mathrm{q}-$ features lies in $18 \mathrm{q} 22-$ 23. Later, they were able to refine this region to an approximate $6 \mathrm{Mb}$ segment within $18 \mathrm{q} 23 .^{2}$ However, the clinical picture of $18 q-$ patients is extremely variable, rendering a precise prediction of the clinical outcome impossible, even when the extent of the deletion is determined. ${ }^{134}$ Among the factors contributing to this phenotypic variability, the genetic background of affected patients, environmental factors, and possibly genomic imprinting of genes in $18 \mathrm{q}$ may play a role. The selective expression of the paternal or maternal allele of a gene responsible for a phenotypic feature $e^{5-7}$ might influence the phenotype of $18 \mathrm{q}-$ patients, depending on whether the mutation arose in the maternal or paternal germline. Most of the $18 \mathrm{q}-$ patients have a paternal deletion. ${ }^{8}$ Assuming deletions originate with the same frequency in the maternal and paternal germline, imprinting of maternal genes could explain a more severe phenotype in patients with a paternal deletion, leading to a higher detection rate.

Evidence for imprinting in 18q came from linkage studies of bipolar affective disorder (BPAD). While several reports have shown linkage to $18 \mathrm{q},{ }^{9-15}$ in some studies most of the linkage evidence derived from families with affected phenotypes in only the paternal lineage and from marker alleles in $18 \mathrm{q} 11$ and $18 \mathrm{q} 21$ transmitted on the paternal chromosome. $^{9101316}$ Genomic imprinting might explain the uniparental linkage, if critical maternal genes are imprinted (inactivated) and thus inheritance of a BPAD gene predisposes to the illness only if it is inherited from the father. Hence, depending on the exact location, imprinted genes in $18 \mathrm{q}$ would be strong candidates for the 18q- syndrome and for BPAD.
Encouraged by these observations, we started a PCR based screen in distal $18 \mathrm{q}$ to test for imprinting by analysing 22 expressed sequence tagged sites (ESTs) within 18q22-23. The ESTs consisted of unidentified as well as identified transcripts, including the myelin basic protein (MBP, MIM 159430), the galanin receptor (GALNR, MIM 600377), cerebellin 2 (CBLN2, MIM 600433), cytochrome b5, and the nuclear factor of activated $\mathrm{T}$ cells (NF-ATc, MIM 600489). The ESTs were chosen mainly because of their location within the $18 \mathrm{q}-$ critical region and their expression in brain which is severely affected in the $18 \mathrm{q}-$ syndrome. ${ }^{17-19}$ The strategy is similar to the one described by Wevrick and Francke, ${ }^{20}$ who showed that transcription of the small nuclear ribonucleoprotein associated polypeptide $\mathrm{N}$ (SNRPN) in peripheral blood lymphocytes and Epstein-Barr virus (EBV) transformed lymphoblastoid cell lines of Prader-Willi syndrome patients is abolished. We tested for expression by PCR analysis of cDNA derived from lymphoblastoid cell lines of 18q- patients using specific EST primers that are only present in one copy in these patients.

EBV transformed cell lines derived from three patients with $18 \mathrm{q}$ deletions (patients 11,17 , and 18 ) have been previously described. The breakpoint of sample 11 is located proximal to D18S214 and D18S269 at approximately 80 $\mathrm{cM}$, the breakpoint of sample 18 is located proximal to D18S165 and D18S252 at approximately $100 \mathrm{cM}$, and the breakpoint of sample 17 is located proximal to D18S299 between the two other breakpoints. ${ }^{1}$ An EBV transformed cell line from a subject with a normal karyotype was used as a control (C). A lymphoblastoid cell line derived from a Prader-Willi syndrome patient (GM09189) who has a deletion involving the SNRPN gene, $\operatorname{del}(15)(\mathrm{pter} \rightarrow$ q11.2::q13 $\rightarrow$ qter), was obtained from the Coriell Cell Repository.

Cytoplasmic RNA was prepared using a kit (RNeasy, Qiagen, Hilden) according to the manufacturer's instructions. Subsequently, RNA was treated with DNAse I (AGS, Heidelberg) to remove any residual genomic DNA. cDNA synthesis was performed by using the MMLV reverse transcriptase (Promega, Madison) according to the manufacturer's protocol. 


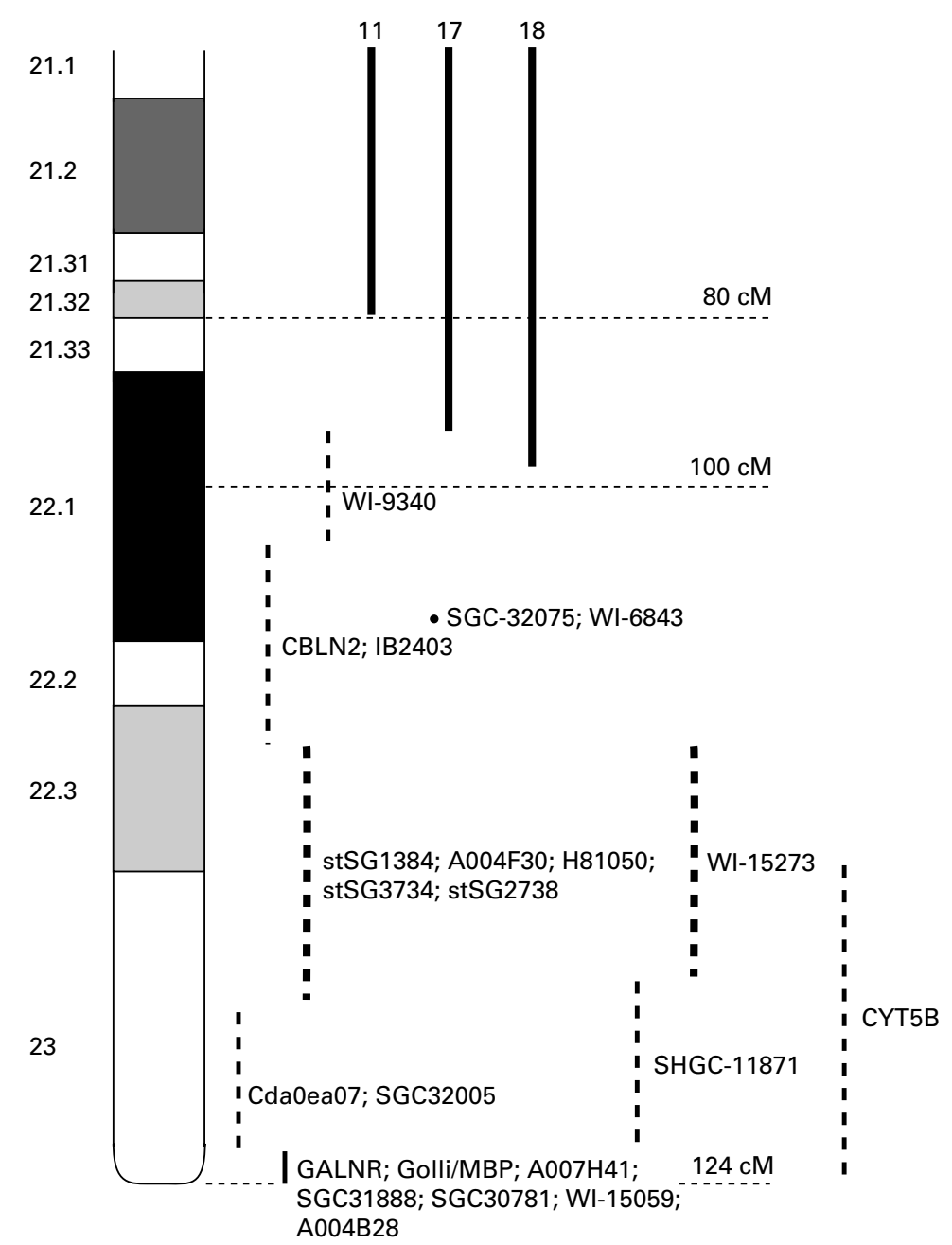

Figure 1 Schematic drawing of distal human chromosome 18q. The truncated chromosomes of the patients in this study are shown at the top; the approximate map positions of the ESTs tested are indicated by dashed bars on the right.

ESTs that mapped in 18q22.2-qter were identified from the gene map/Unigene map database of the National Center for Biotechnology Information (NCBI), National Institutes of Health (http://www.ncbi.nlm.nih.gov/ SCIENCE96/ and http://www.ncbi.nlm.nih.gov/UniGene/ Hs.Home.html). EST primer sequences were obtained from the websites of the Radiation Hybrid Database, European Bioinformatics Institute, Hinxton, UK (www.EBI.ac.uk/RHdb/index.html), and of the Whitehead Institute Center for Genome Research, Boston, MA, USA (www.genome.wi.mit.edu/). Three additional sets of oligonucleotides were used for controls. MBP-PCR1/2 (5'-GGA CCT CGT GAA TTA CAA TC-3' and 5'-ATT TAC CTA CCT GTT CAT CC-3') amplifies a polymorphic region 5' of the $M B P$ gene that is not transcribed. SNRPN-A/B (5'AGA TGG CCG AAT CTT CAT TG-3' and 5'-AGC AAC ACC AGA CCC AAA AC-3') amplifies a $150 \mathrm{bp}$ segment of the SNRPN gene that is known to be maternally imprinted. ${ }^{20}{ }^{21}$ Finally $\beta$-actin-A/B (5'-TCG TGC GTG ACA TTA AGG AG-3' and 5'-AGC ACT GTG TTG GCG TAC AG-3') are primers derived from exon 4 and exon 5 of the $\beta$-actin gene, respectively, and will amplify a 274 bp product only in RNA samples.

PCR analyses were performed in $1 \times \mathrm{Q}$ buffer, $1 \times \mathrm{Q}$ solution (Qiagen, Hilden), $0.1 \mathrm{mmol} / 1 \mathrm{dNTPs}$ (Pharmacia, Uppsala), $0.02 \mathrm{U} / \mu 1$ Platinum Taq DNA polymerase (Life Technologies, Rockville) in a total volume of $25 \mu \mathrm{l}$ in a Perkin Elmer DNA Thermal Cycler (Perkin Elmer, Norwalk). Optimal primer concentrations and annealing tempera- tures were established before testing. Cycling was performed for 30 seconds at $95^{\circ} \mathrm{C}, 30$ seconds at the appropriate annealing temperature, and 30 seconds at $72^{\circ} \mathrm{C}$ for 34 cycles. Amplification products were analysed on a $3 \%$ agarose gel.

Three cell lines containing $18 \mathrm{q}$ deletions were used for imprinting analysis (fig 1 ). The origin of the deletion had been previously determined using polymorphic markers. ${ }^{1}$ Samples 11 and 18 contain paternally derived rearrangements while sample 17 contains a maternally derived rearrangement. The hemizygous deletion in all three cell lines includes the region 18q22.1-qter. ${ }^{1}$ cDNA was prepared from RNA for each of the three cell lines as well as a cell line containing a normal karyotype. To ensure that the RNA samples were free of genomic DNA contamination, PCR analysis was first performed using primers for a region that is located $5^{\prime}$ of the MBP gene. Amplification was not observed in any of the samples but was observed in genomic DNA controls (data not shown), indicating the lack of DNA contamination in the RNA samples. To ensure that cDNA samples were not degraded, PCR was performed using primers derived from two exons of the $\beta$-actin gene. Amplification of the appropriate size product was seen with all cDNA samples (data not shown).

Twenty two ESTs that mapped to 18q22.2-qter were analysed for imprinting. Table 1 lists the ESTs that were tested as well as the composite results. Nine ESTs did not produce amplification products in the sample derived from a subject with a normal karyotype. Fig $2 \mathrm{~A}$ shows a 


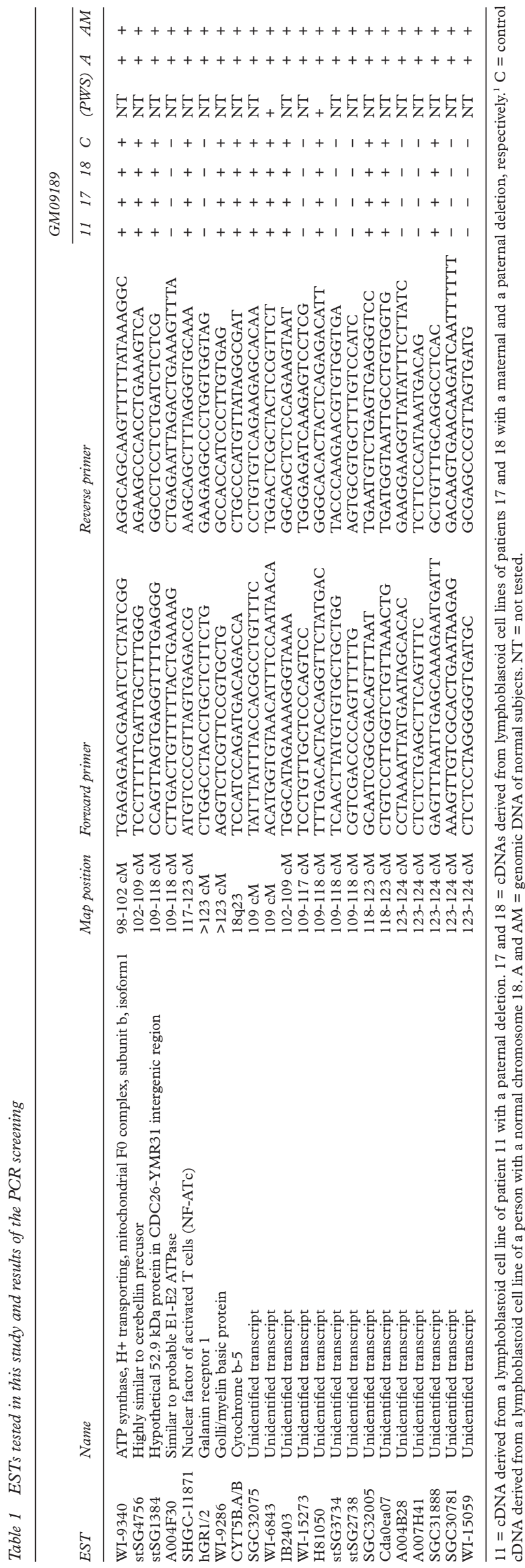

A

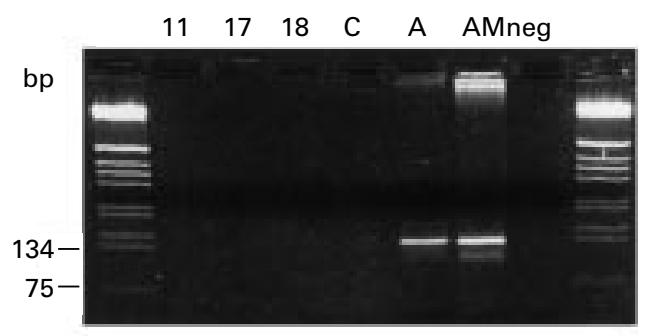

B
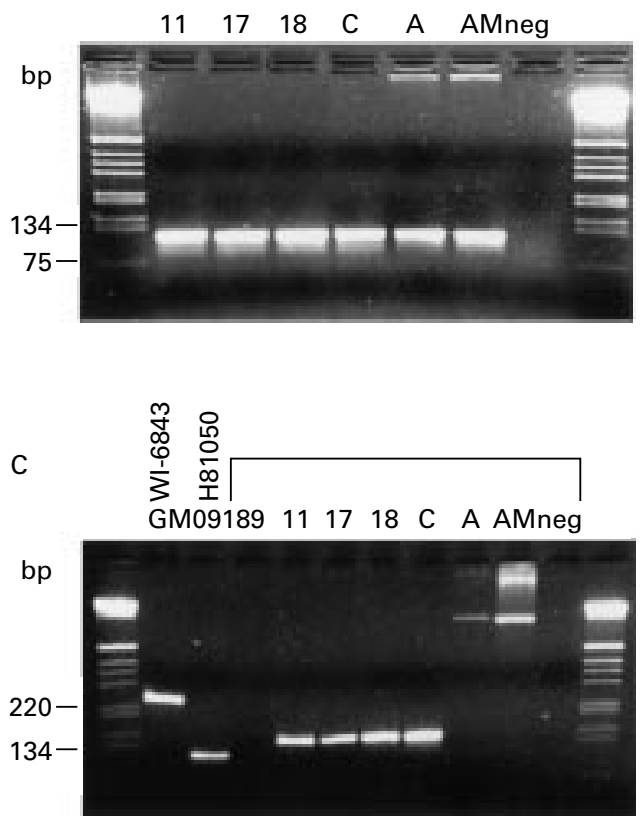

Figure 2 Imprinting analysis of $18 q$ genes. PCR analysis of $c D N A$ derived from patients with maternal $18 q$ deletions (patient 17), paternal $18 q$ deletions (patient 11 and 18), or normal control $(C)$ is shown. Amplification using genomic DNA from two normal subjects ( $A$ and $A M$ ) as well as a sample lacking any DNA input (neg) are shown. Size markers are included in each gel. (A) EST A007H41. (B) EST WI-9340. (C) Amplification using a cDNA derived from a patient with Prader-Willi syndrome (GM09189) and a paternal 15q deletion is shown. Amplification with two $18 q$ ESTs (WI-6843 and H81050) are shown as well as amplification using SNRPN primers, a known maternally imprinted gene.

representative result from EST A007H41. This showed that the genes from which these ESTs were derived were not expressed in lymphoblastoid cells. Appropriate amplification was observed when genomic DNA was used, showing that the lack of amplification was not the result of inappropriate PCR conditions.

The remaining 13 ESTs all produced an amplification product in the sample derived from a subject with a normal karyotype. For all 13 ESTs, amplification was observed in the samples that contained either maternally or paternally derived deletions. A representative result from EST WI-9340 is shown in fig $2 \mathrm{~B}$. This showed that imprinting did not occur in lymphoblastoid cells for the 13 genes that were tested.

To ensure that imprinting could be detected, PCR analysis was performed using primers derived from the SNRPN gene which is known to be maternally imprinted. As shown in fig 2C, no amplification was observed in GM09189, a cell line derived from a Prader-Willi syndrome patient, which contains a paternally deleted 
chromosome 15 . Since the remaining homologue is maternally imprinted, $S N R P N$ is not expressed and therefore no amplification was observed. ESTs that mapped to $18 \mathrm{q}$ (WI-6843 and H81050) did amplify, showing that amplification could be obtained from the RNA sample.

In this study, 13 genes that mapped to the distal region of chromosome 18 were investigated to determine whether they might show an imprinting effect. All 13 genes were expressed from the single remaining allele, regardless of whether it was maternally or paternally derived. The basis for the experiments was that there is significant clinical variability in patients with $18 \mathrm{q}$ deletions. It is possible that imprinting may play a role in this variability.

A clear phenotypic distinction between subjects bearing a paternal and a maternal deletion was not previously possible. ${ }^{1}$ In addition, translocation mouse models did not show any evidence for imprinting in distal MMU18, ${ }^{22}{ }^{23}$ which represents the syntenic region of $18 \mathrm{q} 23$. However, in the study by Strathdee et $a l,{ }^{1}$ only very limited numbers of patients were available and the extent of the deletion differed in almost all of them. Also, imprinting is not always conserved between mouse and $\operatorname{man}^{24}$ and there are at least three human genes that have been shown to be imprinted despite their location within a region excluded from imprinting by translocation studies in mice. ${ }^{2325-27}$ This is probably because of difficulties in detecting more subtle phenotypic alterations in animal models.

The lack of detection of an imprinting effect can be interpreted in several ways. First, imprinting of certain genes in 18q does exist, but we did not test these genes. We do not know whether any of the genes tested are involved in the phenotype of the $18 \mathrm{q}-$ syndrome, although the galanin receptor, the myelin basic protein, cytochrome $5 \mathrm{~b}$, and NF-ATc have been proposed to be candidates. ${ }^{19} 2829$ In our study, 13 of the 22 ESTs distal to $100 \mathrm{cM}$ were informative compared to about 36 genes or so found in this region, according to the NCBI Unigene map. Thus, we cannot exclude other imprinted genes in 18q22-23, though in many cases clusters of genes are imprinted and might therefore be easier to detect when testing a set of genes that are distributed over a chromosomal region. Second, imprinting of genes in $18 \mathrm{q}$ may be restricted to certain tissues or developmental stages. Since only RNA from lymphoblastoid cell lines was tested, we may have missed imprinting that occurred in other tissues. While local and temporal restrictions of imprinting are well known, ${ }^{30-36}$ EBV transformation of lymphocytes does not seem to modify imprinting mechanisms, as has been shown for SNRPN, ${ }^{20} 3738 P A R-1$ and PAR-5, and IPW. ${ }^{39}$ Thus, the method described here should at least be able to detect ubiquitous imprinting of genes and all imprinting phenomena that affect lymphocytes. Finally, it is possible that there is simply no imprinting in the region investigated. If this holds true, we have to conclude that mechanisms such as modifying genes outside $18 \mathrm{q}$ and environmental factors influence the phenotypic picture of $18 \mathrm{q}-$ patients. In this case, we may have to consider that the parent of origin effects in bipolar disorder linked to $18 \mathrm{q}$ represent statistical artefacts, an assumption consistent with observations by Durner and $\mathrm{Abreu}^{40}$ and McMahon $e t a l,{ }^{41}$ who did not observe a consistently paternal parent of origin effect.

Clinical heterogeneity is well known in chromosomal syndromes. The parental origin of the rearrangement has been reported to influence the phenotype in a number of cases. Among them are the paternal duplication of 11 pterp15.4 which results in Beckwith-Wiedemann syndrome (MIM 130650), ${ }^{42}$ and monosomy 15q11-q13 which results in Prader-Willi syndrome (MIM 176270) if the paternal chromosome is affected and in the clinically different
Angelman syndrome (MIM 105830) if the maternal chromosome is affected. ${ }^{43}$ More subtle influences of imprinted genes on the phenotype might be involved in other chromosomal rearrangements ${ }^{44}$ like the deletion associated retinoblastoma, which displays slower tumour progression if the maternal allele is deleted, ${ }^{45}$ suggesting that imprinted genes close to $R B$ might influence tumour growth. Kato et $a l^{25}$ showed that the serotonin receptor 2 (HTR2) gene, which is located within the rearranged chromosomal region in $13 \mathrm{q} 14$, is paternally imprinted. The authors speculate that HTR2 is a gene promoting the growth of retinoblastoma and that tumour progression depends on whether its active or inactive copy is retained. Other examples are Williams syndrome patients with a deletion of $7 q 11.23$ who display significantly more severe growth retardation and microcephaly if the arrangement is maternally derived, ${ }^{46}$ and Turner syndrome patients $(45, \mathrm{X})$ who show significantly poorer verbal and higher order executive function skills when the retained $\mathrm{X}$ chromosome is of maternal origin. ${ }^{47} 48$

This study presents the initial analysis for identifying imprinted genes in 18q. Although this study did not identify any imprinted genes, the approach can easily be expanded to investigate additional genes. The ability to detect imprinted genes located on other chromosomes in lymphoblastoid cells shows that the approach used here is a viable one and should be continued as a method for investigating whether imprinting effects might be involved in the clinical variability of the $18 \mathrm{q}-$ syndrome.

We thank Nora Speer and Leonie Rieger for technical assistance, Christian Rees and Miriam Pietrzyk for valuable discussions, and Professor W Engel for support.

ROBERT MAIWALD* JOAN OVERHAUSER†
FRANCO LACCONE*

*Institute of Human Genetics, University of Göttingen, Gosslerstrasse 12d, D-37073 Göttingen, Germany

†Department of Biochemistry and Molecular Biology, Thomas fefferson University, 233 S 10th Street Suite 209, Philadelphia, PA 19107, USA

Correspondence to: Dr Maiwald, rmaiwal@gwdg.de

1 Strathdee G, Zackai EH, Shapiro R, Kamholz J, Overhauser J. Analysis of clinical variation seen in patients with $18 \mathrm{q}$ terminal deletions. Am $\mathcal{F}$ Med Genet 1995;59:476-83.

2 Strathdee G, Sutherland R, Jonsson JJ, et al. Molecular characterization of patients with 18q23 deletions. Am f Hum Genet 1997;60:860-8.

3 Qazi QH, Madahr C, Alvi S, McGann B. Distal 18q deletion without clinical findings of 18q- syndrome. Ann Genet 1980;23:60-3.

4 Kohonen-Corish M, Strathdee G, Overhauser J, McDonald T, Jammu V. A Kohonen-Corish $M$, Strathdee $G$, Overhauser J, McDonald T, Jammu V. A
new deletion of $18 \mathrm{q} 23$ with few typical features of the $18 \mathrm{q}-$ syndrome. $\mathcal{F}$ Med Genet 1996;33:240-3.

5 Surani MA. Imprinting and the initiation of gene silencing in the germ line. Cell 1998;93:309-12.

6 Bartolomei MS, Tilghman SM. Genomic imprinting in mammals. Annu Rev Genet 1997;31:493-525.

7 Sapienza C, Hall JG. Genetic imprinting in human disease. In: Scriver CR, ed. The metabolic and molecular bases of inherited disease. New York: McGraw-Hill, 1995:437-58

8 Cody JD, Pierce JF, Brkanac Z, et al. Preferential loss of the paternal alleles in the 18q- syndrome. Am f Med Genet 1997;69:280-6.

9 Collins JS, Go RC. Disease classification and transmission effects on linkage analyses in the NIMH1 bipolar disorder pedigrees. Genet Epidemiol 1997; 14:587-92.

10 Dorr DA, Rice JP, Armstrong C, Reich T, Blehar M. A meta-analysis of chromosome 18 linkage data for bipolar illness. Genet Epidemiol 1997;14:617-22

11 Haghighi F, Li W, Fann CS. Affected-sib-pair analyses of bipolar disorder using data on chromosome 18. Genet Epidemiol 1997;14:641-6.

12 MacKinnon DF, Xu J, McMahon FJ, et al. Bipolar disorder and panic disorder in families: an analysis of chromosome 18 data. Am F Psychiatry 1998; 155:829-31.

13 Stine OC, Xu J, Koskela R, et al. Evidence for linkage of bipolar disorder to chromosome 18 with a parent- of-origin effect. Am f Hum Genet 1995;57: 1384-94.

14 Ewald H, Mors O, Koed K, Eiberg H, Kruse TA. Susceptibility loci for bipolar affective disorder on chromosome 18? A review and a study of Danish families. Psychiatr Genet 1997;7:1-12.

15 Freimer NB, Reus VI, Escamilla MA, et al. Genetic mapping using haplotype, association and linkage methods suggests a locus for severe bipolar disorder (BPI) at 18q22-q23. Nat Genet 1996;12:436-41.

16 Gershon ES, Badner JA, Detera-Wadleigh SD, Ferraro TN, Berrettini WH. Maternal inheritance and chromosome 18 allele sharing in unilineal bipolar illness pedigrees. Am $\mathcal{F}$ Med Genet 1996;67:202-7. 
17 Vogel H, Urich H, Horoupian DS, Wertelecki W. The brain in the 18q- syndrome. Dev Med Child Neurol 1990;32:732-7.

$18 \mathrm{Mahr}$ RN, Moberg PJ, Overhauser J, et al. Neuropsychiatry of $18 \mathrm{q}-$ (1996;67:172-8.

19 Gay CT, Hardies LJ, Rauch RA, et al. Magnetic resonance imaging demonstrates incomplete myelination in $18 \mathrm{q}$ - syndrome: evidence for myelin basic protein haploinsufficiency. Am $\mathcal{F}$ Med Genet 1997;74:422-31

20 Wevrick R, Francke U. Diagnostic test for the Prader-Willi syndrome by SNRPN expression in blood. Lancet 1996;348:1068-9.

21 Reed ML, Leff SE. Maternal imprinting of human SNRPN, a gene deleted in Prader-Willi syndrome. Nat Genet 1994;6:163-7.

22 Cattanach BM, Beechey CV. Imprinting, In: Reik W, Surani MA, eds. Frontiers in molecular biology. Oxford: Oxford University Press, 1997:118-45.

23 Beechey CV, Cattanach BM. Genetic and physical imprinting map of the mouse. Mouse Genome 1997;95:100-5.

24 Lyle R. Gametic imprinting in development and disease. F Endocrinol 1997; 155:1-12.

25 Plass C, Shibata H, Kalcheva I, et al. Identification of Grf1 on mouse chromosome 9 as an imprinted gene by RLGS-M. Nat Genet 1996;14:106 -

26 Barlow DP, Stoger R, Herrmann BG, Saito K, Schweifer N. The mouse insulin-like growth factor type-2 receptor is imprinted and closely linked to the Tme locus. Nature 1991;349:84-7

27 Giddings SJ, King CD, Harman KW, Flood JF, Carnaghi LR. Allele specific inactivation of insulin 1 and 2 , in the mouse yolk sac, indicates imprinting. Nat Genet 1994;6:310-13.

28 Cody JD, Hale DE, Brkanac Z, Kaye CI, Leach RJ. Growth hormone insufficiency associated with haploinsufficiency at 18q23. Am 7 Med Genet 1997;71:420-5

29 Strathdee G, Yoshikawa T, Detera-Wadleigh S, Sutherland R, Grady D, Overhauser J. Identification of candidate genes involved in the $18 \mathrm{q}-$ Overhauser J. Identification of candidate genes involve

syndrome. Am f Hum Genet 1996;59(suppl):313(abst 1821).
30 Kishino T, Lalande M, Wagstaff J. UBE3A/E6-AP mutations cause Kishino T, Lalande M, Wagstaff J. UBE3A

31 Albrecht U, Sutcliffe JS, Cattanach BM, et al. Imprinted expression of the murine Angelman syndrome gene, Ube3a, in hippocampal and Purkinje neurons. Nat Genet 1997;17:75-8.

32 Rougeulle C, Glatt H, Lalande $M$. The Angelman syndrome candidate gene, UBE3A/E6-AP, is imprinted in brain. Nat Genet 1997;17:14-15.

$33 \mathrm{Vu}$ TH, Hoffman AR. Imprinting of the Angelman syndrome gene, UBE3A, is restricted to brain. Nat Genet 1997;17:12-13.
34 Williamson CM, Schofield J, Dutton ER, et al. Glomerular-specific imprinting of the mouse gsalpha gene: how does this relate to hormone resistance in Albright hereditary osteodystrophy? Genomics 1996;36:280-7.

35 Bunzel R, Blumcke I, Cichon S, et al. Polymorphic imprinting of the serotonin-2A (5-HT2A) receptor gene in human adult brain. Brain Res Mol Brain Res 1998;59:90-2.

36 Hemberger M, Redies C, Krause R, Oswald J, Walter J, Fundele RH. H19 and Igf2 are expressed and differentially imprinted in neuroectodermderived cells in the mouse brain. Dev Genes Evol 1998;208:393-402.

37 Kawame H, Gartler SM, Hansen RS. Allele-specific replication timing in imprinted domains: absence of asynchrony at several loci. Hum Mol Genet 1995;4:2287-93.

38 Sutcliffe JS, Nakao M, Christian S, et al. Deletions of a differentially methylated $\mathrm{CpG}$ island at the SNRPN gene define a putative imprinting control region. Nat Genet 1994;8:52-8.

39 Wevrick R, Kerns JA, Francke U. Identification of a novel paternally expressed gene in the Prader-Willi syndrome region. Hum Mol Genet 1994; 3:1877-82.

40 Durner M, Abreu P. Exploring linkage of chromosome 18 markers and bipolar disease. Genet Epidemiol 1997;14:623-7.

41 McMahon FJ, Hopkins PJ, Xu J, et al. Linkage of bipolar affective disorder to chromosome 18 markers in a new pedigree series. Am 7 Hum Genet 1997;61:1397-404

42 Reik W, Maher ER. Imprinting in clusters: lessons from BeckwithWiedemann syndrome. Trends Genet 1997;13:330-4.

43 Nicholls RD, Saitoh S, Horsthemke B. Imprinting in Prader-Willi and Angelman syndromes. Trends Genet 1998;14:194-200.

44 Morison IM, Reeve AE. A catalogue of imprinted genes and parent-oforigin effects in humans and animals. Hum Mol Genet 1998;7:1599-609.

45 Kato MV, Ishizaki K, Shimizu T, Toguchida J, Kaneko A, Sasaki MS Delayed development of retinoblastoma associated with loss of a maternal allele on chromosome 13. Int f Cancer 1995;64:3-8.

46 Perez Jurado LA, Peoples R, Kaplan P, Hamel BC, Francke U. Molecular definition of the chromosome 7 deletion in Williams syndrome and parentof-origin effects on growth. Am ₹ Hum Genet 1996;59:781-92.

47 Skuse DH, James RS, Bishop DV, et al. Evidence from Turner's syndrome of an imprinted X-linked locus affecting cognitive function. Nature 1997;387: $705-8$

48 Chu CE, Donaldson MD, Kelnar CJ, et al. Possible role of imprinting in the Turner phenotype. F Med Genet 1994;31:840-2

\section{Renal angiomyolipomata and learning difficulty in tuberous sclerosis complex}

EDITOR-Tuberous sclerosis complex (TSC) is a dominantly inherited disease of high penetrance, characterised pathologically by the presence of hamartomata in multiple organ systems. Well known clinical manifestations include epilepsy, learning difficulties, behavioural problems, and skin lesions. Many patients have renal lesions, usually angiomyolipomata (AML), which can cause clinical problems secondary to haemorrhage or by compression and replacement of healthy renal tissue, which rarely causes end stage renal failure. ${ }^{1}$ Cysts, polycystic renal disease, and renal carcinoma can also occur. Polycystic disease has an early onset clinically and is the result of large contiguous deletions on chromosome 16 affecting both the TSC2 gene and the gene for adult onset polycystic kidney disease. ${ }^{2}$ Tuberous sclerosis complex exhibits genetic heterogeneity. ${ }^{3}$ Mutations in two recently identified genes, TSC1 at 9q34 and TSC2 at $16 \mathrm{p} 13$, each result in an apparently similar phenotype, although recent work has suggested that mutations in TSC 2 may be associated with more severe disease. ${ }^{4}$ Both genes are tumour suppressor genes, the strongest evidence for this being the loss of heterozygosity around the normal gene at $9 \mathrm{q} 34$ or $16 \mathrm{p} 13$ in hamartomata from tuberous sclerosis patients. ${ }^{56}$ There is evidence that the severity of learning difficulties in tuberous sclerosis complex is related to the number of hamartomata in the brain. ${ }^{7}$ Until now, no one has reported on a correlation between the severity of the phenotype in two or more organs. We report on a correlation between renal hamartomata and learning difficulties in a population based sample of tuberous sclerosis complex patients (table 1 ). f Med Genet 2000;37:156-157

As part of a larger prevalence study that began in 1985 , patients identified with tuberous sclerosis complex and living in the Bath Health District have been followed longitudinally. All patients have undergone at least one abdominal ultrasound examination, performed by the authors, during the last two years. We investigated the association between angiomyolipomata and intellectual impairment because of an apparent association we had noticed in our clinical work with TSC patients (table 1). We made no attempt to explore any other associations. The presence of learning difficulty in this population was ascertained as previously described. ${ }^{8}$ The correlation between renal angiomyolipomata and learning difficulty was analysed using a two sided Fisher's exact test (table 2). Of 22 patients known to be alive and living in the Bath Health District in August 1998, nine had learning difficulties and all had angiomyolipomata. Thirteen patients were of normal intellect and five of these had angiomyolipomata $(p=0.006)$.

This apparent association between renal angiomyolipomata in tuberous sclerosis complex and learning difficulties has not previously been noted. The association reaches statistical significance despite the small numbers

Table 1 Angiomyolipomata and learning difficulties in TSC patients

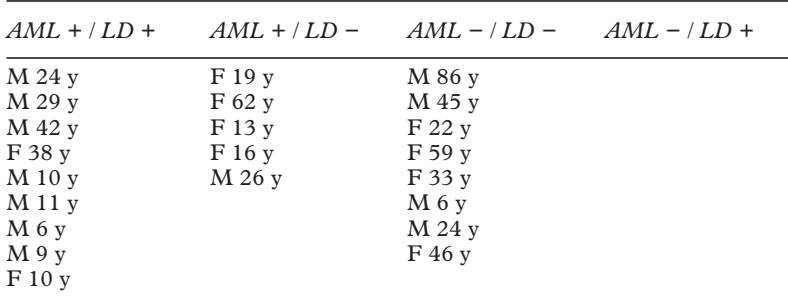

$\mathrm{AML}=$ angiomyolipoma

$\mathrm{LD}=$ learning difficulty.

$M=$ male.

$\mathrm{F}=$ female.

$\mathrm{y}=$ years. 
Table 2 Two sided Fisher's exact test

\begin{tabular}{lll}
\hline & \multicolumn{2}{l}{ Learning difficulties } \\
\cline { 2 - 3 } & + & - \\
\hline Renal angiomyolipomata & & \\
+ & 9 & 5 \\
- & 0 & 8 \\
$\mathrm{p}=0.006$ & &
\end{tabular}

involved in the study and remains significant even when two patients of normal intellect and isolated renal cysts are transferred from the unaffected to affected groups $(\mathrm{p}=0.046)$; it is possible that renal cysts may form in TSC because renal tubules are blocked by small renal angiomyolipomata. We do not think there is an absolute correlation between learning difficulty and renal angiomyolipomata; we have patients outside the Bath district with learning difficulties and no renal pathology.

The age range in our population is $6-86$ years (median 24 years). Using Wilcoxon rank sum tests we found no significant association between age and learning difficulty $(p=0.09)$ or between age and the presence of AMLs $(p=0.09)$ in this population. Similarly there is no evidence of a significant relationship between gender and either learning difficulty $(p=0.1)$ or AML presence $(p=1.0)$ when the relationships are independently investigated using Fisher's exact tests. There is no reason to suppose, therefore, that the association described between intellectual impairment and renal angiomyolipomata is confounded significantly by either gender or age in this sample.

One explanation for the observed correlation would be that certain patients with tuberous sclerosis complex have an increased propensity to the formation of hamartomata resulting both in more cerebral tubers (and therefore a higher risk of learning difficulties) and in a greater likelihood of renal angiomyolipoma formation. Previously, patients with tuberous sclerosis complex and learning difficulty appear to have had a reduced life expectancy; epidemiological surveys have consistently shown lower than expected numbers of elderly tuberous sclerosis patients with learning difficulties. ${ }^{8}$ We believe this is because of an increased death rate among this group from epilepsy, brain tumours, and intercurrent illness. However, with changing attitudes to the management of patients with learning difficulties, improved management of epilepsy, and more vigilant surveillance, more of these patients survive into adulthood. One implication of our finding is that we will see an increase in complications from renal hamartomata as more tuberous sclerosis patients with intellectual difficulties survive for longer.

FINBAR J K O'CALLAGHAN * MICHAEL NOAKES + JOHN P OSBORNE*

*Bath Unit for Research in Paediatrics, Children's Centre, Royal United Hospital, Combe Park, Bath BA1 3NG, UK

tDepartment of Radiology, Royal United Hospital, Combe Park, Bath BA1 3NG, UK

Correspondence to: Professor Osborne

1 Steiner MS, Goldman SM, Fishman EK, Marshall FF. The natural history of renal angiomyolipoma. F Urol 1993;150:1783-6.

2 Sampson JR, Maheshwar MM, Aspinwall R, et al. Renal cystic disease in tuberous sclerosis: role of the polycystic kidney disease 1 gene. Am f Hum Genet 1997;61:843-51.

3 Povey S, Burley MW, Attwood J, et al. Two loci for tuberous sclerosis: one on 9q34 and one on 16p13. Ann Hum Genet 1994;58:107-27.

4 Jones AC, Daniells CE, Snell RG, et al. Molecular genetic and phenotypic Jones AC, Daniells CE, Snell RG, et al. Molecular genetic and phenotypic
analysis reveals differences between TSC1 and TSC2 associated familial analysis reveals differences between TSC1 and TSC2 associated
and sporadic tuberous sclerosis. Hum Mol Genet 1997;6:2155-61.

5 Green A, Johnson P, Yates J. Loss of heterozygosity on chromosome 16 p13.3 in hamartomas from tuberous sclerosis patients. Nat Genet 1994; 6:193-6

6 Green A, Johnson P, Yates J. The tuberous sclerosis gene on chromosome 9q34 acts as a growth suppressor. Hum Mol Genet 1994;3:1833-4.

7 Goodman M, Lamm SH, Engel A, Shepherd CW, Gomez MR. Cortical tuber count: a biomarker indicating cerebral severity of tuberous sclerosis complex. $\mathcal{F}$ Child Neurol 1997;11:85-90.

8 Webb DW, Fryer AE, Osborne JP. Morbidity associated with tuberous sclerosis: a population study. Dev Med Child Neurol 1996;38:146-55.

\section{Clinical geneticists' attitudes and practice towards testing for breast cancer susceptibility genes}

EDITOR-Cancer genetics, and in particular breast cancer genetics, is the fastest expanding discipline within clinical genetics. Cancer referrals now constitute a third of all referrals to most clinical genetics centres. Currently there are no national guidelines on predictive testing for $B R C A 1$ and $B R C A 2$. Several members of the same family may be seen in different centres and offered different clinical management. Such differences may in part be attributable to differences in funding of genetic services and testing at the service or research level, but it is clear that this area also involves various ethical dilemmas that may well be viewed differently by different practitioners. In order to investigate the nature and degree of variation that exists in practice and attitudes among clinical geneticists, we have undertaken a survey of all clinical geneticists in the United Kingdom who deal with cancer genetics.

Four clinical case scenarios were devised from the authors' own clinical experience to assess attitudes and practice towards breast cancer gene testing. Questionnaires were sent to 57 geneticists in the United Kingdom, representing all specialist registrar and consultants involved in cancer genetics. Each was asked to respond to questions relating to each scenario and to state the reasons for their decisions. Forty seven completed questionnaires were received ( $83 \%$ compliance). All clinical genetics centres in the UK were represented by at least one response. In three instances a joint response involving more than one geneticist from a centre was returned. The four clinical cases are given below. For each case the salient points raised by selected respondents for arriving at their decision are given.

Case 1. A woman has been shown to carry a pathogenic mutation in the BRCA1 gene. She is 9 weeks pregnant and requests a prenatal test to see whether the fetus also carries this mutation. Participants were asked whether they would be prepared to offer prenatal testing after appropriate counselling.

Twenty four $(51 \%)$ respondents stated that they would be prepared to offer prenatal testing to the woman after counselling. Fifteen (32\%) said they would not and $17 \%$ did not know what their action would be. Most of the respondents who would offer such testing indicated that if the counsellors had given all the relevant information, it was up to the woman to make a decision. Most commented that the woman's experience of cancer in the family was likely to be a strong motivating factor in the decision to request prenatal diagnosis and that counsellors were not in a position to deny this experience. Many also commented that a pregnancy could be terminated anyway for "social" 
reasons and that refusal to offer predictive testing would therefore not necessarily prevent a termination. The following quotations illustrate some of the opinions given.

"I would find the idea difficult but after counselling and with full information it is the couple's decision. Any other stance in a country accepting social termination is difficult." "If we are not prepared to offer prenatal diagnosis we cannot engage in counselling." "In some families the cancer burden is enormous. The child may not only have to grow up without a mother but also with the possibility of developing the disease herself." "It is within the patient's rights." "Prenatal tests are offered for other potentially treatable conditions of late onset."

Most of the respondents who did not know what their action would be raised the issue that it depended on why she wished to have prenatal testing. They felt that testing might be appropriate if the woman would definitely proceed to termination should the mutation be detected in the fetus. If there was doubt about this, however, or the test was done for information only, then respondents would be reluctant to offer testing, since continuation of the pregnancy would be interfering with the autonomy of the child and future adult. In effect, such testing would equate to doing a predictive test on a child who might not want to know its own genetic status.

"I would attempt to dissuade her but if she was still insistent then I would feel obliged to offer a termination. There are many other disorders where I would not be entirely happy with offering a prenatal diagnosis/ termination but if after careful counselling the patient still wants it then I would. After all a woman can have a termination for essentially social reasons anyway."

Those who felt it would be inappropriate to offer prenatal $B R C A$ testing focused on the uncertainties that still lie with such information. These are summarised by the following quotations.

"Not a lethal disorder with no treatment. If testing and no termination takes place the child could face insurance problems during life." "Even if positive, penetrance is only $80-90 \%$ maximum. There are screening options and treatment options." "The reasons for not doing the test are: (1) incomplete penetrance and uncertainties of penetrance in some cases, and (2) the availability of measures for early cancer detection and prophylaxis which although experimental will almost certainly improve over the next 30 years." "Future child should have autonomy." "Adult onset disease treatable if detected early. Prophylactic surgery a possibility." "Effects of mutations uncertain and too far in the future."

Some responses were more directive: "Would try to talk her out of it."

Many respondents also felt that legally they could not offer a termination if the result showed that the fetus carried the pathogenic mutation as summarised in the following quotation.

"The 1967 Abortion Act does not apply here, therefore we have to rely on case law to do a termination for fetal abnormality. I would be concerned about the legal position here as I don't think the fetus would necessarily be classed as severely handicapped."

Case 2. The mother of a 15 year old girl had undergone $B R C A 1$ testing because of a very strong family history of breast and ovarian cancer and a pathogenic BRCA1 mutation had been identified. The 15 year old who was quite mature for her age and well informed about her risks was very keen to have a predictive test so that she could "plan her life accordingly". Participants were asked whether they would offer this 15 year old girl a predictive test.

Thirty four percent $(16 / 47)$ of the respondents were prepared to offer predictive testing. However, 23 (49\%) were not prepared to do so. The remaining seven (15\%) did not know what action they would take. Those who were prepared to offer predictive testing gave the following reasons.

"At the age of 15 a young person can be considered 'Gillick' competent and able to give consent to treatment or investigation. If the girl has thought it through I would be prepared to do the test." "I believe there is benefit for her knowing at the age of 15 , potential reassurance and potential lifestyle chances, usage of the contraceptive pill and planning etc if she is a gene carrier." "After exploring her reasons for doing it now."

For those who would not be prepared to offer predictive testing the reasons given included the following.

"Risk is not imminent. She is likely to have $10-20$ years before it does become imminent and circumstances may have changed dramatically by then. It is hard to see how any immediate decisions, for example, life plans, would be influenced by knowledge of carrier status at 15." "Thin end of wedge. Why not a mature 12 year old?" "I would advise more time for reflection. It could well affect her self image if she has a positive result and relationships with mother, and she is at a critical stage in her education which could be disrupted by a positive gene test." "I would encourage her to wait. When life has been planned, that is, with regard to jobs, mortgages, life insurance etc." "Her risk is negligible at this age." "Would try very hard to dissuade her, explaining it wouldn't make any difference to her management." "There is little information about the effects of predictive testing in young people and the psychological sequelae." "If she thinks this information will help plan her life she needs more explanation."

Case 3. A woman who does not fit the local criteria for genetic testing for $B R C A 1$ or $B R C A 2$ is insistent that she wants testing even though the limitations of the test have been explained. She asks if the test can be done privately? Respondents were asked whether they would be prepared to give her the name of a commercial company providing testing.

Seventy percent $(32 / 47)$ questioned were prepared to give her this information. Most respondents felt that they could not deny knowledge on principle and it was her decision to spend her own money. Furthermore, the information is relatively easily accessible and withholding such information could heighten any anxiety. Some of the particular comments made were as follows.

"If the company find the mutation other family members have their risk altered/increased and then would probably be referred to the genetics service." "This is already done for paternity testing. I see it as an obligation to tell the client of any other resources."

Twenty five percent (12/47) stated they would not be prepared to give the name of a commercial company to the woman. Some felt that providing this information might be seen as an endorsement of the company and that a commercial company does not provide any form of counselling.

"I would be concerned about equity of access to the service and queue jumping by using private labs if people could afford it." "I am prejudiced against a commercial company that does not provide general counselling support for such testing. I would point out the disadvantages of a commercial company for whose quality control operating standards and lack of counselling support I could not comment." "We are not agents for private companies." "If she does not fit the local criteria, the chances of finding a mutation are low. Her anxiety will not be resolved by an inappropriate and almost certainly uninformative test." 
Only two respondents (4\%) gave don't know as a response and no comments were received in respect of this action.

Case 4. It was stated that a 27 year old woman attended the clinic because her identical twin sister had just developed carcinoma of the breast. Their mother also had breast cancer at the age of 45 . She died at the age of 50 . There was no blood or tissue available from the mother. Respondents were asked what risk would they give the consultand of developing breast cancer. They were also asked whether they would be prepared to offer any genetic testing and if so which test or tests they would offer and why?

The majority $(31 / 47,66 \%)$ stated that the woman's lifetime breast cancer risk was between 70 and $80 \%$, which from published evidence seems to be the most accurate figure. ${ }^{1}$ However, some estimates were as low as $30 \%$ and others as high as $90 \%$. Respondents were not asked how they arrived at these figures. Most of the respondents $(34 / 47,72 \%)$ would offer genetic testing. Their management of the case in respect of gene testing showed differences.

"Can only offer diagnostic testing, not predictive testing." "Would do diagnostic test in sister and then predictive test in patient, because there is a chance they are not actually identical." "Confirm they are identical and then treat as a diagnostic test." "I would counsel the two sisters in parallel but genetically the risks are identical, the only difference is the penetrance issue of this gene in identical sibs." "We could not give any good news, we could only give bad news."

Only two of the respondents commented on the difficulty of interpreting a negative test.

We carried out this survey to assess variability among cancer geneticists within the United Kingdom in attitudes and practice towards breast cancer gene testing. The results of our survey clearly show that differences do exist. The differences seen in response to the clinical scenarios were, perhaps not surprisingly, most pronounced in relation to situations having the greatest ethical component.

Prenatal testing is offered for a number of genetic disorders. With the notable exception of disorders such as Huntington's disease, for which there is no disease modifying treatment, interest in prenatal testing has centred on severe diseases presenting early in life. Attitudes to prenatal testing for adult disease for which some form of treatment exists varied considerably. The issue of testing for breast cancer susceptibility genes is further complicated by the fact that such genes are not fully penetrant and that sporadic disease is common in the population.

One of the central themes of genetic counselling laid down in Peter Harper's seminal text is that counselling should be non-directive. ${ }^{2}{ }^{3}$ The aim of genetic counselling is to ensure that people have the necessary facts to enable them to arrive at their own decisions. If one adopts this as the central tenet of the genetic counselling services, it is the person's decision as to whether to have prenatal testing. It may be naive to believe that all genetic counselling is truly non-directive; genetic issues are complex and counsellors' personal opinions may be apparent or inferred from the manner in which the explanation is made. We found it interesting that a large percentage of those surveyed would be reluctant to engage in prenatal counselling for breast cancer susceptibility genes and furthermore that a proportion of clinicians would actively dissuade a woman from pursuing prenatal testing if she was a $B R C A 1$ mutation carrier. This is clear evidence against non-directive counselling.
Informed consent is clearly a central part of any predictive testing programme. The age at which a person can give consent for any medical procedure has been the subject of considerable debate in recent years. In case 2 we presented the hypothetical situation of a girl of 15 requesting a predictive test for $B R C A 1$. Clearly a woman's risk of breast cancer before the age of 25 is small, and therefore it can be deemed that there is no immediate urgency for testing from the perspective of risk. Many of the respondents made this point, some giving it as a reason for not agreeing to offering a predictive test. However, many other reasons contribute to a person's decision to undertake genetic testing and ultimately the issue centres on at what age a person is able to make this type of decision. Some respondents felt that such testing would be illegal at this age; however, both case law (Gillick $v$ West Norfolk and Wisbech AHA, 1986) and statute law (the Children's Act, 1989) allow children under the age of 18 to make independent decisions about themselves if they are deemed "sufficiently mature". One respondent pointed to anecdotal evidence that presymptomatic testing experience in Huntington's disease suggests that all those under the age of 25 who were found to be carriers had major psychological problems subsequently. The only published evidence seems to point to a greater difficulty in coping with the disease when it is first learnt of during adolescence rather than adulthood. ${ }^{4}$ While deferring testing may ensure that the test is not done in haste, any directive counselling in terms of trying to dissuade her clearly runs counter to the Harper ideal of counselling.

Our next scenario concerned private laboratories. Unlike the United States, Britain has little in the way of private genetic services and both counselling and genetic laboratories are largely confined to the National Health Service. It is conceivable that things may change and there may be an increase in private genetic services. Any growth in private genetics is likely to be confined to laboratory tests and a concern here is that it may be unaccompanied by any form of counselling. Furthermore, the motivation by such enterprises is financial remuneration and hence many of those offered tests may be at a low probability of being gene carriers and at a risk not significantly different from that of the general population. It is therefore unlikely that an expansion of the activities of private laboratories will be greeted enthusiastically by clinical geneticists. Whether one should provide the address of such a laboratory if requested to do so is perhaps a different point. The responses to this question indicated a number of views relating to this issue. Some felt that giving such information could be construed as an endorsement of a private company. Alternatively, a failure to convey the address could be seen as a paternalistic attitude and erosion of free choice.

In a recent article Rosser et $a \bar{l}$ highlighted that there are differences in the estimation of risk made by geneticists for identical family histories of breast cancer. We also found evidence of this from the responses to case 4 . While most risks were given as between 70 and $80 \%$, estimates ranged from $30-90 \%$. Case 4 concerned gene testing in a family with an identical twin. This case was chosen to illustrate the fact that the distinction between diagnostic and predictive testing becomes rather blurred in the context of one affected and one unaffected identical twin. Several respondents $(13 \%, 6 / 47)$ did not comment on this and said they would proceed with predictive testing once a mutation had been detected in the identical twin. Clearly, if the twins are really identical, then only diagnostic testing is possible even in the unaffected twin. It is perhaps not surprising that there were considerable differences in participants' responses. 
The field of cancer genetics is rapidly evolving and clinical practice is developing to meet the challenge of this changing field. It is perhaps not surprising that differences in clinical practices exist; however, there will be pressure for these to coalesce to similar policy. We hope that this article will draw to attention to some areas in breast cancer genetics where there are considerable differences in opinion and serve as a discussion for helping to devising guidelines for those in the field.

ANNEKE M LUCASSEN* RICHARD $S$ HOULSTON

${ }^{\star}$ Department of Clinical Genetics, Churchill Hospital, Oxford OX3 7LF, $U K$
†Section of Cancer Genetics, Institute of Cancer Research, Sutton, Surrey SM2 $5 N G, U K$

1 Ford D, Easton DF, Stratton M, et al. Genetic heterogeneity and penetrance analysis of the BRCA1 and BRCA2 genes in breast cancer families. The Breast Cancer Linkage Consortium. Am f Hum Genet 1998;62:676-89.

2 Harper PS, Clarke AJ. Genetics, society and clinical practice. Oxford: Bios Scientific Publishers, 1997:16-31.

3 Harper PS. Practical genetic counselling. Oxford: Butterworth Heinemann, 1993:3-17.

4 Van der Steenstraten IM, Tibben A, Roos R, et al. Predictive testing for Huntington's disease: nonparticipants compared with participants in the Dutch program. Am f Hum Genet 1994;55:618-25.

5 Rosser EM, Hurst JA, Chapman CJ. Cancer families: what risks are they given and do the risks affect management? F Med Genet 1996;33:977-80. 